\title{
Comparison of Inorganic Chlorine in the Southern Hemispheric lowermost stratosphere during Late Winter 2019
}

\author{
Markus Jesswein ${ }^{1}$, Heiko Bozem ${ }^{2}$, Hans-Christoph Lachnitt ${ }^{2}$, Peter Hoor $^{2}$, Thomas Wagenhäuser ${ }^{1}$, \\ Timo Keber ${ }^{1}$, Tanja Schuck ${ }^{1}$, and Andreas Engel ${ }^{1}$ \\ ${ }^{1}$ University of Frankfurt, Institute for Atmospheric and Environmental Sciences, Frankfurt, Germany \\ ${ }^{2}$ Johannes Gutenberg University of Mainz, Institute for Atmospheric Physics, Mainz, Germany \\ Correspondence: Markus Jesswein (jesswein@iau.uni-frankurt.de)
}

\begin{abstract}
Inorganic chlorine $\left(\mathrm{Cl}_{\mathrm{y}}\right)$ is the sum of the degradation products of long-lived chlorinated source gases. These include the reservoir species $\left(\mathrm{HCl}\right.$ and $\left.\mathrm{ClONO}_{2}\right)$ and active chlorine species (i.e. $\mathrm{ClO}_{\mathrm{x}}$ ). The active chlorine species drive catalytic cycles that deplete ozone in the polar winter stratosphere. This work presents calculations of inorganic chlorine $\left(\mathrm{Cl}_{\mathrm{y}}\right)$ derived from chlorinated source gas measurements on board the High Altitude and Long Range Research Aircraft (HALO) during the

5 Southern hemisphere Transport, Dynamic and Chemistry (SouthTRAC) campaign in late winter and early spring 2019. Results are compared to $\mathrm{Cl}_{\mathrm{y}}$ of the Northern Hemisphere derived from measurements of the POLSTRACC-GW-LCYCLE-SALSA (PGS) campaign in the Arctic winter of 2015/2016. A scaled correlation was used for PGS data, since not all source gases were measured. $\mathrm{Cl}_{\mathrm{y}}$ from a scaled correlation was compared to directly determined $\mathrm{Cl}_{\mathrm{y}}$ and agreed well. An air mass classification based on in situ $\mathrm{N}_{2} \mathrm{O}$ measurements allocates the measurements to the vortex, the vortex boundary region, and mid-latitudes. Although the Antarctic vortex was weakened in 2019 compared to previous years, $\mathrm{Cl}_{\mathrm{y}}$ reached $1687 \pm 20 \mathrm{ppt}$ at $385 \mathrm{~K}$, therefore up to around $50 \%$ of total chlorine could be found in inorganic form inside the Antarctic vortex, whereas only $15 \%$ of total chlorine could be found in inorganic form in the southern mid-latitudes. In contrast, only $40 \%$ of total chlorine could be found in inorganic form in the Arctic vortex during PGS and roughly $20 \%$ in the northern mid-latitudes. Differences inside the respective vortex reaches up to $565 \mathrm{ppt}$ more $\mathrm{Cl}_{\mathrm{y}}$ in the Antarctic vortex 2019 than in the Arctic vortex 2016 (at comparable distance to the local tropopause). As far as is known, this is the first comparison of inorganic chlorine within the respective polar vortex. Based on the results of these two campaigns, the difference of $\mathrm{Cl}_{\mathrm{y}}$ inside the respective vortex is significant and larger than reported inter annual variations.
\end{abstract}

\section{Introduction}

The Antarctic ozone hole is a recurring event, which was first documented by Farman et al. (1985) and has been observed anually since the 1980-ies. Polar ozone depletion is pre-dominantly driven by anthropogenic chlorine and bromine from longlived halogenated species (Molina and Rowland, 1974; Engel et al., 2018b). The primary mechanisms for the depletion of ozone $\left(\mathrm{O}_{3}\right)$ in the polar stratosphere are the catalytic cycles with halogen-containing free radicals as chain carriers (Molina et al., 1987). Chlorine substances, which are involved in rapid ozone depletion are $\mathrm{Cl}, \mathrm{Cl}_{2}, \mathrm{ClO}, \mathrm{ClOOCl}$, and $\mathrm{OClO}$, and can 
be summarized as $\mathrm{ClO}_{\mathrm{x}}$. Additionally, hydrogen chloride $(\mathrm{HCl})$ and chlorine nitrate $\left(\mathrm{ClONO}_{2}\right)$ contribute to ozone depletion as they enable the production of active chlorine within heterogeneous reactions on polar stratospheric clouds (PSC) during polar winter with low temperatures (e.g., Crutzen and Arnold, 1986; Molina et al., 1987). They are therefore called reservoir species. Chemically active chlorine $\left(\mathrm{ClO}_{\mathrm{x}}\right)$ and the reservoir gases together form the total inorganic chlorine $\left(\mathrm{Cl}_{\mathrm{y}}\right)$, also called available chlorine.

The size of the Antarctic ozone hole varies and depends on the amount of $\mathrm{Cl}_{\mathrm{y}}$ and on stratospheric temperature and dynamics (Newman et al., 2004). However, $\mathrm{Cl}_{\mathrm{y}}$ data is sparse in the polar stratosphere and likewise the amount of measurements of total organic chlorine $\left(\mathrm{CCl}_{\mathrm{y}}\right)$. In contrast, there are many more observations from e. g. remote sensing instruments of nitrous oxide $\left(\mathrm{N}_{2} \mathrm{O}\right)$, which can be used to determine $\mathrm{Cl}_{\mathrm{y}}$. A common tool to determine $\mathrm{Cl}_{\mathrm{y}}$ is the usage of scaled correlations. Strahan et al. (2014) used Microwave Limb Sounder (MLS) $\mathrm{N}_{2} \mathrm{O}$ measurements and a scaled correlation between $\mathrm{N}_{2} \mathrm{O}$ and $\mathrm{Cl}_{\mathrm{y}}$ from Schauffler et al. (2003) to show that interannual variability of $\mathrm{Cl}_{\mathrm{y}}$ for 2004-2012 (-200 to + $\left.150 \mathrm{ppt}\right)$ can be up to 10 times larger than the expected 20-22 ppt/yr decline rate due to the Montreal Protocol. Strahan and Douglass (2018) used again MLS measurements of $\mathrm{O}_{3}, \mathrm{HCl}$, and $\mathrm{N}_{2} \mathrm{O}$ to show that Antarctic $\mathrm{Cl}_{\mathrm{y}}$ levels have decreased by $223 \pm 93$ ppt over a 9 year period (2013-2016 compared to 2003-2007), equivalent to an annual rate of $25 \pm 10 \mathrm{ppt} / \mathrm{yr}(\sim 0.8 \% / \mathrm{yr})$. It is thus important to know whether and how correlations can be transferred from another time period and possibly another region (other hemisphere). Due to the phase-out of the long-lived chlorinated species, $\mathrm{Cl}_{\mathrm{y}}$ shows a long term negative trend, whereas $\mathrm{N}_{2} \mathrm{O}$ exhibits a positive trend. This leads to a changing relationship between $\mathrm{Cl}_{\mathrm{y}}$ and $\mathrm{N}_{2} \mathrm{O}$ with time, which must be taken into account. The concept of mean arrival time $\left(\Gamma^{*}\right)$ can be used to normalize correlations of chemically active tracers and scale them to the time of interest (Plumb et al., 1999). The normalized correlations do not change with time and the resulting scaled correlations are used to calculate $\mathrm{Cl}_{\mathrm{y}}$.

Ozone destruction in the stratosphere is closely linked to the polar vortex. The absence of solar ultraviolet heating during polar winter leads to a temperature difference and consequently to a latitudinal pressure gradient between polar and midlatitudes stratosphere (Schoeberl and Hartmann, 1991). The result is a state with a strong westerly wind in the stratosphere (polar night jet), which acts as a transport barrier, and strong latitudinal gradients of potential vorticity and long-lived substances like $\mathrm{N}_{2} \mathrm{O}$ (Hartmann et al., 1989). This isolation of the vortex leads to different concentrations of trace gases within the vortex compared to those in the stratosphere of the mid-latitudes. The effect is further enhanced by diabatic descent over the winter, leading to substantially different distributions of trace gases inside and outside the vortex on the same potential temperature $(\Theta)$ surface. The polar vortex core can thus be described as a quasi-isolated vessel, separated from the mid-latitude stratosphere by the vortex boundary region. In order to differentiate between air masses inside and outside the vortex, a classification of the measurements is needed.

In this study, inorganic chlorine $\left(\mathrm{Cl}_{\mathrm{y}}\right)$ was quantified in the Arctic and Antarctic vortex. A new air mass classification system was used for this purpose, based on high resolution in situ measurements during the campaigns, to map measurements to the vortex, vortex boundary region and mid-latitudes. Results of the SouthTRAC campaign from the Antarctic winter/spring 2019 are used to compare $\mathrm{Cl}_{\mathrm{y}}$ of the Southern Hemisphere with $\mathrm{Cl}_{\mathrm{y}}$ of the Northern Hemisphere from measurements of the POLSTRACC-GW-LCYCLE-SALSA (PGS) campaign in the Arctic winter of 2015/2016. An overview of the atypical 
Antarctic vortex 2019 can be found in Wargan et al. (2020). The evolution of the 2015/2016 Arctic vortex is reported in Manney and Lawrence (2016). Since not all source gases were measured during PGS, a scaled correlation was used and showed the capability of this method as a proxy for sparse data in comparison to the determination from the source gases used for SouhTRAC measurements. Sect. 2 is a brief introduction to the SouthTRAC campaign and the observations used for this study. Sect. 3 explains the identification of vortex, vortex boundary, and mid-latitude region. The derivation of inorganic chlorine and the comparison of the methods, the distribution during the late Antarctic winter of 2019, and the comparison of Arctic and Antarctic $\mathrm{Cl}_{\mathrm{y}}$ is discussed in Sect 4.. Sect 5. sums up and concludes the findings.

\section{The SouthTRAC campaign}

In late winter and early spring of 2019, the Southern hemisphere Transport, Dynamics, and Chemistry (SouthTRAC) campaign took place to investigate dynamical and chemical composition aspects of the Antarctic upper troposphere and lower stratosphere (UTLS) and gravity waves up to the mesosphere (Rapp et al., 2020). Flights were performed with the German High Altitude and LOng Range Research Aircraft (HALO), which is capable to reach an altitude of around $14.5 \mathrm{~km}$ or $420 \mathrm{~K}$ potential temperature. To meet the dynamical and chemical objectives (see https://www.pa.op.dlr.de/southtrac/science/scientific-objectives/), the aircraft was based in Rio Grande (RGA), Argentina $\left(53^{\circ} \mathrm{S}, 67^{\circ} \mathrm{W}\right.$ ). Thus, regions for gravity-wave breaking (Southern Atlantic and Eastern Pacific) and Antarctica were in the range of the aircraft. The campaign was split in two phases. The first phase took place in September 2019 to target the dynamical objectives (e.g., Rapp et al., 2020). The second phase took place in November 2019 to, among others, sample polar vortex remnants. Furthermore, the transfer flights were part of the scientific flights and provide additional information for all objectives.

HALO performed 23 scientific flights with in total 183 hours of measurement time. Nine of these flights were transfer flights from Oberpfaffenhofen (EDMO), Germany, to Rio Grande (RGA), Argentina, and back via Sal (SID), Cabo Verde, and Buenos Aires (EZE), Argentina, (see Fig. 1a). The remaining flights were local flights with ten in the first phase and three in the second phase. The second phase was terminated early due to technical problems but still provided 27 hours of measurements. Thus, it was possible to investigate a region of around $36-70^{\circ} \mathrm{S}$ and $32-84^{\circ} \mathrm{W}$ (see Fig. 1b). The airplane reached a maximum potential temperature of $409 \mathrm{~K}$ during the campaign.

\subsection{Airborne measurements}

HALO was equipped with a wide range of in situ and remote-sensing instruments. Beside the scientific instruments, installed for the measurement campaign (also known as payload), the Basic Halo Measurements and Sensor System (BAHAMAS) is part of HALO. BAHAMAS is installed permanently and provides meteorological and aircraft parameters along the flight trajectory (DLR, 2020). The following is a brief explanation of the instruments and the type of measurements that were used for the present work. 


\subsection{Halocarbons}

The Gas chromatograph for Observational Studies using Tracers (GhOST) is a two-channel gas chromatographic instrument. The first channel combines an isothermally operated gas chromatograph (GC) with an electron capture detector (ECD) to measure $\mathrm{SF}_{6}$ and $\mathrm{CFC}-12$ at a time resolution of $1 \mathrm{~min}$ (hereinafter referred to as GhOST-ECD). A similar set-up was used during the SPURT campaign (Bönisch et al., 2009; Engel et al., 2006). The second channel is a combination of temperature programmed GC with a quadrupole mass spectrometer (QP-MS, hereinafter referred to as GhOST-MS). Because of very small mole fractions of the halocarbons, a cryogenic pre-concentration system is installed prior to the GC (Obersteiner et al., 2016; Sala et al., 2014). GhOST was operated successfully during several aircraft campaigns to mainly target brominated halocarbon species, as discussed in Keber et al. (2020). For the SouthTRAC campaign, the ionisation mode was changed from negative chemical ionization (NCI) to electron impact ionization (EI) to record full mass spectra. For each substance, one molecular fragment is selected for which the chromatographic peak is not disturbed by other substances. Furthermore, the MS was operated in selected ion monitoring (SIM), scanning pre-selected mass fractions at a preset retention time window. A larger sample volume is needed in EI mode compared to NCI mode. The change of ionization decreased the time resolution from 4 min to 6 min per measurements cycle, of which 147 seconds are needed for sampling air. The performance of the GhOST-MS channel for the chlorinated substances used in this work is shown in Table 1. Displayed are the precisions and detection limits measured shortly before the campaign in the laboratory. Additionally, based on in flight calibration, a precision during the flight can also be calculated. As the conditions in the airplane are more variable than in a laboratory, especially when changing the flight level, this affects the precisions of the measurements. The frequency of calibration measurements during a flight is much lower than in the laboratory, making it less stable than the laboratory value. Therefore, precision drops for most of the substances by up to a factor of 4 . The exceptions are CFC-113 and methyl chloroform. Methyl chloroform shows a significantly better precision during the campaign, whereas the precision CFC-113 measurement was much poorer. As CFC-113 elutes near water the amount of water in the analytical system should be kept as low as possible, since water causes an increase of the baseline and disturbs the sensitivity. CFC-12 with the GhOST-ECD channel was measured with a precision of $0.2 \%$. The instrument was tested for non-linearities and memory effect and correction was done where necessary (see Sala et al. (2014) for details). Mixing ratios in this work are reported as dry mixing ratios on AGAGE (Advanced Global Atmospheric Gases Experiment) scales.

\section{$2.3 \quad \mathrm{~N}_{2} \mathrm{O}$}

Measurements of $\mathrm{N}_{2} \mathrm{O}$ were performed with the University of Mainz Airborne Quantum Cascade Laser-spectrometer (UMAQS), which also provided data for $\mathrm{CH}_{4}, \mathrm{CO}, \mathrm{CO}_{2}$ and OCS during SouthTRAC. The instrument is based on direct absorption spectroscopy using a continuous-wave quantum cascade laser with a sweep rate of $2 \mathrm{kHz}$ (Müller et al., 2015). During SouthTRAC the instrument was calibrated in-situ against two standards of different concentrations, which are compared against primary standards (NOAA) prior and after campaign phases. 
Under typical flight conditions at flight level $\mathrm{N}_{2} \mathrm{O}$ was measured with an overall uncertainty of $0.6 \mathrm{ppb}$ relative to the calibration standards. The noise of the $1 \mathrm{~Hz}$ data was of $0.1 \mathrm{ppb}$ (1-sigma). Note that this is an upper limit since the data are post-flight corrected for drift effects based on the in-flight calibrations.

\section{Defining vortex, vortex boundary and mid-latitude region}

Chlorine activation occurs in the coldest regions of the stratosphere and is therefore typically co-located with the polar vortex. Furthermore, as the polar night jet acts as a barrier, air composition is different inside and outside the vortex. High concentrations of reactive halogenated substances can be maintained inside the vortex because there is little mixing with the surrounding area. During the HALO flights, the aircraft encountered air masses with different characteristics due to their origin. To make systematic conclusion about the distribution of trace gases, a reliable, accurate method of separating the measurements in terms of their region is needed. For this reason, the following describes how air masses have been classified using highly resolved in situ measurements.

\subsection{Air mass classification by in situ measurements}

The maximum gradient of potential vorticity (PV) is a commonly used indicator to define the location of the vortex edge, also known as the Nash criterion (Nash et al., 1996). Unfortunately, the usage of PV has a major drawback as it is a model-derived quantity with a rather coarse resolution. Hence, small-scale features like vortex filaments with different chemical compositions may not be taken into account. In this work, an extended version of the vortex definition by Greenblatt et al. (2002a) is used instead. The technique by Greenblatt et al. (2002a) uses the tight correlation between $\mathrm{N}_{2} \mathrm{O}$ and potential temperature $(\Theta)$ to determine the inner edge of the vortex boundary. A tracer like $\mathrm{N}_{2} \mathrm{O}$ exhibits a horizontal gradient across the vortex edge in the stratosphere with lower mixing ratios inside the vortex and higher mixing ratios outside the vortex. It can be measured in situ with a sufficiently high time resolution to reveal small structures in the atmosphere. Air inside the vortex is isolated from the surroundings leading to a strong vertical gradient due to strong diabatic descent inside the vortex. Additionally, the isolation inside the vortex benefits mixing on isentropic surfaces and therefore a small variability on isentropes (variability of about $6 \mathrm{ppb}$ (Greenblatt et al., 2002a)). The low mixing ratios inside the vortex are a result of diabatic descend of high altitude air with less $\mathrm{N}_{2} \mathrm{O}$. In contrast, the mid-latitudes vertical gradient is weak and more variable as it is influenced by tropical and polar air (Krause et al., 2018; Marsing et al., 2019). In between there is a transition region (vortex boundary region), which is influenced by the vortex as well as by mid-latitudes. Towards tropopause altitudes, the $\mathrm{N}_{2} \mathrm{O}$ profiles of vortex and mid-latitudes merge and differentiation becomes difficult.

Based on the method of Greenblatt et al. (2002a), one flight is chosen to generate a vortex reference profile. This flight should at best be completely in the vortex. However, during the SouthTRAC campaign there was no flight that only sampled vortex air. In addition, there is an interest in not only distinguishing between vortex and non-vortex air, but also in assigning the campaign measurements to the vortex, vortex boundary region, and mid-latitudes. For this reason, several flights were used to create reference profiles for the vortex and mid-latitudes. Stratospheric transport and mixing is related to the isentropic surfaces 
whereas mixing at the extratropical tropopause affects the lowest $25 \mathrm{~K}$ relative to the local tropopause. Therefore, classification was done with two vertical coordinates, potential temperature $(\Theta)$ and potential temperature above the local tropopause $(\Delta \Theta)$.

The vortex reference profile (see Fig. 2) was generated by using all flights, which had contact to the vortex core. Data from these flights were pre-filtered by taking only the measurements polewards of $60^{\circ} \mathrm{S}$ equivalent latitude and $20 \mathrm{~K}$ above the local tropopause. The lowest levels of potential temperature above the local tropopause are strongly influenced by extra-tropical tropospheric air, i. e. the tropopause mixing layer in the lowermost stratosphere (Hoor et al., 2005). With an iterative filter procedure (see supporting information) the lower envelope of the remaining measurements is obtained and is used to generate the vortex profile function (Werner, 2006). For the mid-latitudes profile (see Fig. 2), all flights were taken into account, focusing only on measurements between $-40^{\circ}$ and $-60^{\circ}$ equivalent latitude and again $20 \mathrm{~K}$ above the local tropopause. This time, the upper envelope of the measurements was evaluated by the iteration procedure to build a reference profile function for the midlatitudes. A more detailed description of the creation of reference profiles can be found in the supporting information. The two reference profiles in $\Theta$-coordinates are displayed in Figure 2a, the two reference profiles in $\Delta \Theta$-coordinates in Figure $2 \mathrm{~b}$.

In general, it cannot be assumed that a single $\mathrm{N}_{2} \mathrm{O}$ vortex profile can be representative for the entire winter. Subsidence of the vortex air by several kilometers due to radiative cooling (Schoeberl and Hartmann, 1991) leads to a changing $\mathrm{N}_{2} \mathrm{O}$ profile throughout the polar winter. The diabatic descent, however, starts very early in late fall and maximum decent rates occur in the late fall/early winter phase (Greenblatt et al., 2002b). The campaign took place in late winter and a further diabatic descent is not expected. Therefore, only one reference vortex profile was generated for the campaign. Looking at flights from the first and second phase of the SouthTRAC campaign, the vortex profile fits for both phases.

A vortex and mid-latitudes reference $\mathrm{N}_{2} \mathrm{O}$ data set $\left(\mathrm{N}_{2} \mathrm{O}_{\text {vor }}\right.$ and $\left.\mathrm{N}_{2} \mathrm{O}_{\text {mid }}\right)$ can be calculated by using the fit functions for the vortex and mid-latitudes profile and the $\mathrm{N}_{2} \mathrm{O}$ measurements of the UMAQS instrument of all flights. The following then applies for each $\mathrm{N}_{2} \mathrm{O}$ measurement: if the mixing ratio is below the respective $\mathrm{N}_{2} \mathrm{O}_{\text {vor }}$ with a prescribed cutoff value, then it is assigned to the vortex. Otherwise, if the mixing ratio is above the respective $\mathrm{N}_{2} \mathrm{O}_{\text {mid }}$ with an associated variability, than it is assigned to mid-latitudes. Mixing ratios above the respective $\mathrm{N}_{2} \mathrm{O}_{\text {vor }}$ with a prescribed cutoff value and below the respective $\mathrm{N}_{2} \mathrm{O}_{\text {mid }}$ with an associated variability are assigned to the boundary region. For the mixing ratios, where $\mathrm{N}_{2} \mathrm{O}_{\text {vor }}$ with a prescribed cutoff value and $\mathrm{N}_{2} \mathrm{O}_{\text {mid }}$ with an associated variability overlap, these measurements can not be fully assigned to one region.

\subsection{Overview of the sample regions}

In 2019, extraordinary meteorological conditions led to a sudden rise in stratospheric temperatures over Antarctica. This minor sudden stratospheric warming (minor SSW) event affected the shape, location and strength of the polar vortex. From midAugust to early September 2019, the polar vortex has been displaced and weakened towards the eastern South Pacific and South America (Safieddine et al., 2020; Wargan et al., 2020). The SouthTRAC campaign flights took place from early September to early October and in the first half of November and were thus timed close to the minor SSW event and captured the late evolution of the Antarctic polar vortex.

Figure 3 displays an overview of air mass classification over the SouthTRAC campaign (classification in $\Theta$-coordinates). Measurements below $20 \mathrm{~K}$ of $\Delta \Theta$ are not classified and are not taken into account here. There are no $\mathrm{N}_{2} \mathrm{O}$ measurements 
available from flight ST08 on September 11th, so no classification was possible. Vortex air sampling varies from flight to flight, depending on the objective of each flight. Vortex and boundary region were sampled in both phases of the campaign, but more extensive in the first phase with flights sampled mostly inside the vortex or vortex boundary region (e. g. flight ST15 on 29 September or flight ST16 on 30 September). In general, vortex air represents about $25 \%$ of flight time in the stratosphere and vortex boundary layer about $18 \%$. More than half of the flight time in the stratosphere was in mid-latitudes air $54 \%$. The use of the $\Delta \Theta$-coordinates for the air mass classification leads to similar percentage division (not shown here).

\section{Inferred inorganic chlorine}

The metric describing the combined effect of all ozone depleting substances (ODS) as an equivalent amount of inorganic chlorine in the stratosphere, related to tropospheric source gases in a simple matter, is the equivalent effective stratospheric chlorine (EESC) (Newman et al., 2007; Daniel et al., 1995). Changes to the EESC are mainly due to $\mathrm{Cl}_{\mathrm{y}}$, as $\mathrm{Br}_{\mathrm{y}}$ makes up a smaller fraction (Strahan et al., 2014). The 6 min time resolution of the MS channel makes it difficult to detect fine structures such as filaments and small scale dynamical perturbations. Therefore, an up-sampling of the MS data to the time resolution of the ECD channels was performed before calculating $\mathrm{Cl}_{\mathrm{y}}$.

\subsection{Up-sampling GhOST-MS measurements}

The GhOST-MS measurements have a time resolution of $6 \mathrm{~min}$ of which the enrichment and therefore the sampling of air took around 147 seconds. With a maximum cruising speed of around $258 \mathrm{~m} / \mathrm{s}$, this means sampling air along a distance of approximately $38 \mathrm{~km}$ per measurement during enrichment. This could lead to a rather coarse resolution where fine structures like filaments are sometimes not well resolved.

Measuring CFC-12 on both the ECD and MS channel of the instrument allows to up-sample the measurements of the organic source gases by using the higher resolved measurements of CFC-12 from the ECD channel. Measurements of CFC-12 on the ECD channel not only have a higher time resolution of $1 \mathrm{~min}$, but also a better precision than on the MS channel. As shown in Fig. 4, the correlation between CFC-12 measurements of both channels for all flights is linear over the whole range of mixing ratios with a coefficient of determination of $R^{2}=0.968$. Firstly, for each organic source gas, a fit function is calculated based on the correlation with CFC-12 measurements on the GhOST-MS channel for all flights (correlations contained in the supporting information). Secondly, these fit functions are then used together with the CFC-12 measurements of the ECD channel to calculate the up-sampled mixing ratios of the organic source gases. Flight ST14 from 26 September in Fig. 5 is an example to demonstrate the benefit of the up-sampling. Displayed are the original measurements of CFC-11 of the MS channel as well as the up-sampled CFC-11 values. The background colors indicate to which region the samples can be assigned (classification in $\Theta$-coordinates), as described in Sect. 3. The up-sampled values show a higher variability and follow well the classification by region. Especially with the sharp gradients, e. g. at 04:10 UTC and at 05:50 UTC in Fig. 5, the original data were not well captured, whereas the up-sampled data resolve the changes. In the following, the up-sampled data are used for further evaluations. 


\subsection{Semi-direct and indirect calculation of inorganic chlorine}

$\mathrm{Cl}_{\mathrm{y}}$ can be calculated as the difference between total chlorine entering the stratosphere and organic chlorine bound in chlorinated hydrocarbons (Eq. 1).

$\chi_{\mathrm{Cly}_{\mathrm{y}}}=\chi_{\mathrm{Cl}_{\mathrm{total}}}-\chi_{\mathrm{CCly}}$

Organic chlorine $\left(\mathrm{CCl}_{\mathrm{y}}\right)$ can be calculated directly from the up-sampled GhOST-MS measurements. Additionally, the mixing ratios at the stratospheric entry point of the major chlorine containing substances $\left(\mathrm{Cl}_{\text {total }}\right)$ must be known. Air enters predominantly through the tropical tropopause layer (TTL). During transport into and within the stratosphere, an air parcel exhibits irreversible mixing and can not be regarded as conserved (Hall and Plumb, 1994). Instead, an air parcel in the stratosphere consists of a multitude of components with different transit times, representing their travel times in the stratosphere since they entered the stratosphere. The distribution of the transit times is called the age spectrum $G$ and the first moment is the mean age $\Gamma$ (Hall and Plumb, 1994). The concept of the age spectrum can be used to determine mean age values based on observations of chemically inert tracers in the stratosphere. For this purpose in addition to the age spectrum, tropospheric time series of the inert tracers are required (Engel et al., 2002). This was done for the SouthTRAC campaign by using $\mathrm{SF}_{6}$ measurements of GhOST-ECD and tropospheric time trends taken from the AGAGE (Advanced Global Atmospheric Gases Experiment) Network (Prinn et al., 2018). Since only the mean age is given, a width parameterization is used to derive the age spectrum by using the ratio of moments $\left(\Delta^{2} / \Gamma\right)$. Hauck et al. (2019) showed that the ratio of moments undergoes seasonal variability and is probably much larger than previous implemented values (e. g. Engel et al., 2002; 0.7 year). A ratio of moments of 1.25 years is chosen here. The age spectrum together with the tropospheric time trend of the substances of interest can be used to calculate the stratospheric mixing ratio, which would be present without chemical degradation and thus represents the entry mixing ratio. In the following, $\mathrm{Cl}_{\mathrm{y}}$ determination from the difference between the entry mixing ratios and $\mathrm{CCl}_{\mathrm{y}}$ from the in situ measurements is referred to as the semi-direct calculation of $\mathrm{Cl}_{\mathrm{y}}$.

For the case no measurements of chlorine containing substances are available, $\mathrm{Cl}_{\mathrm{y}}$ has in the past been calculated based on correlations derived from previous measurement campaigns. For instance Wetzel et al. (2015) and Marsing et al. (2019) used $\mathrm{Cl}_{\mathrm{y}}$ based on a correlation derived from two balloon flights inside the Arctic polar vortex in 2009 and 2011 from a cryogenic whole-air sampler (Engel et al., 2002). In order to account for tropospheric trends the correlations between CFC-12 and the other long-lived substances were adapted with a modified method described in Plumb et al. (1999) using the mean arrival time $\Gamma^{*}$ to derive a correlation function valid for the respective time where the correlation is applied. Plumb et al. (1999) showed, that the age spectrum of an inert tracer is not well suited to describe the propagation of chemically active tracers, into and through the stratosphere. They introduced a modified age spectrum, called the normalized arrival time distribution $G^{*}$, which combines chemical loss and transport. The mean arrival time $\Gamma^{*}$ represents the first moment of this distribution. The mean arrival time $\Gamma^{*}$ for all the relevant chlorine substances can be parameterized in terms of stratospheric lifetime $\tau$ and mean age $\Gamma$ (Plumb et al., 1999). Using $G^{*}$ instead of $G$ and therefore $\Gamma^{*}$ instead of $\Gamma$ is better suited for chemically active 
tracers, because the tail of the transit time distribution is less weighted, especially for substances with shorter stratospheric lifetimes (Engel et al., 2018a; Ostermöller et al., 2017). To transfer the correlations from the balloon observations in 2009 and 2011 to the measurements during SouthTRAC in 2019, the observed mixing ratios are first divided by the respective entry values to derive the normalized mixing ratios. The entry values are calculated by the modified age spectrum and tropospheric time trends from the AGAGE Network for the time of the balloon measurements. Multiplying the normalized mixing rations with the entry mixing ratio for the time during SouthTRAC then allows a comparison to the directly determined correlations during SouthTRAC. Here, we compare the directly observed correlation and semi-direct $\mathrm{Cl}_{\mathrm{y}}$ values from SouthTRAC to the indirectly determined correlations. Note that the indirectly determined values are not only based on observations which have been performed about 10 years earlier but also are from the Northern Hemisphere instead of the Southern Hemisphere. Fig. 6 displays scaled correlations of three long-lived substances against CFC-12. They correspond well to the correlations measured during the SouthTRAC campaign. Therefore, $\mathrm{CCl}_{\mathrm{y}}$ based on correlations with $\mathrm{CFC}-12$ can be used as a good proxy for the amount of inorganic chlorine. As already mentioned earlier, $\mathrm{Cl}_{\text {total }}$ can be derived to calculate $\mathrm{Cl}_{\mathrm{y}}$. A correlation function for the Antarctic late winter 2019 has been derived for the indirect calculation of $\mathrm{Cl}_{\mathrm{y}}$ as a function of $\mathrm{CFC}-12$ mixing ratios (Eq. 2). The coefficients for the correlation function with CFC-12 as the reference substance, based on the balloon measurements, can be taken from Table 2. In addition, the fit coefficients are given if one wants to use $\mathrm{N}_{2} \mathrm{O}$ as the reference. CFC-12 from the GhOST-ECD channel is used to determine inorganic chlorine.

$\chi_{\mathrm{Cly}}=\mathrm{c}_{0}+\mathrm{c}_{1} \chi_{\text {ref }}+\mathrm{c}_{2}\left(\chi_{r e f}\right)^{2}$

Figure 7 shows semi-directly and indirectly determined inorganic chlorine as a function of mean age. $\mathrm{Cl}_{\mathrm{y}}$ values were binned in intervals of 0.2 years and the mean values are displayed. For both methods, inorganic chlorine increases with mean age of air, as more molecules of the organic source gases are converted to the inorganic form. The difference between the two methods is rather small, with less than around 30 ppt difference below 4 years of mean age and a maximum difference of about $65 \mathrm{ppt}$ at 5 years of mean age. The small deviation over the entire range of mean age indicates that adapted correlations from previous measurement campaigns and also from the Northern Hemisphere, lead to comparable values in inorganic chlorine determined for the Southern Hemisphere. Hence the metric can be used for the calculations of $\mathrm{Cl}_{\mathrm{y}}$, where only measurements of CFC-12 are available. Since it was possible during SouthTRAC to measure the organic source gases, the $\mathrm{Cl}_{\mathrm{y}}$ from the direct measurements was used for further evaluation. With the semi-directly determined $\mathrm{Cl}_{\mathrm{y}}$ during SouthTRAC, correlation functions can be determined. Table 2 contains the coefficients for the correlation functions based on CFC-12 and $\mathrm{N}_{2} \mathrm{O}$ as references. The correlation functions are limited to the minimum mixing ratio of the respective reference substance taken during the SouthTRAC campaign. 


\subsection{Chlorine partitioning in the Antarctic winter 2019 lower stratosphere}

Since inorganic chlorine plays a major role in ozone depletion, it is worth investigating its distribution in the Antarctic stratosphere. For the analysis only measurements were taken, which are polewards of $40^{\circ}$ equivalent latitude. As a vertical coordinate $\Theta$ was chosen. All measurements have been binned into $5 \mathrm{~K}$ potential temperature bins between 270 and $420 \mathrm{~K}$ of $\Theta$ (see Fig. 8). Bins which contain less than five data points are not included in the analysis. The uncertainties represented by the errorbars are the $1 \sigma$ standard deviations of the means. Up to the potential temperature at which an air mass classification begins, $\mathrm{Cl}_{\mathrm{y}}$ is given for all measurements. From the potential temperature at which air mass classification begins, $\mathrm{Cl}_{\mathrm{y}}$ is given according to the region. Measurements within the overlap area in the classification (see Fig 2) are counted both as vortex and mid-latitudes measurements.

The inferred $\mathrm{Cl}_{\mathrm{y}}$ throughout the troposphere is close to zero and increases in the tropopause region. The measurements are thus consistent with the global tropospheric time trends from the AGAGE Network. The vertical profiles of vortex, vortex boundary, and mid-latitudes declared measurements show different gradients. In the mid-latitudes, the inorganic chlorine hardly increases between 330 and $390 \mathrm{~K}$ with values between $190 \pm 99 \mathrm{ppt}$ and $270 \pm 117 \mathrm{ppt}$, whereas the increase is stronger between 390 and $400 \mathrm{~K}$ reaching a value of $435 \pm 143 \mathrm{ppt}$. The profile of the vortex boundary region increases in the range from $484 \pm 109$ ppt up to $977 \pm 320 \mathrm{ppt}$ in the $\Theta$ interval of 360 to $395 \mathrm{~K}$. The variability of the vortex boundary profile increases with height. This is partly due to the air mass classification, since the range of values in the vortex boundary region increases with increasing potential temperature (see Fig 2). Inorganic chlorine within the vortex could be obtained from $\Theta$ between 330 to $385 \mathrm{~K} . \mathrm{Cl}_{\mathrm{y}}$ inside the vortex increases significantly up to a value of $1687 \pm 20 \mathrm{ppt}$. Thus, in late winter and early spring at this altitude about half of the recorded chlorine is found in inorganic form, although from a meteorological point of view this year is exceptional with a significantly weakened vortex due to the minor SSW. Accompanying the minor SSW event, the 2019 ozone hole was about 16.4 million $\mathrm{km}^{2}$ in size (NASA Ozone Watch), making it the smallest since its discovery.

\subsection{Comparison of $\mathrm{Cl}_{\mathrm{y}}$ in the Antarctic (SouthTRAC) and Arctic (PGS) polar winter}

To compare $\mathrm{Cl}_{\mathrm{y}}$ in the Antarctic polar vortex and in the Arctic polar vortex, measurements performed on the HALO aircraft during the PGS campaign were used. PGS consisted of the three partial missions POLSTRACC (Polar Stratosphere in a Changing Climate), GW-LCYCLE (Investigation of the Life cycle of gravity waves) and SALSA (Seasonality of Air mass transport and origin in the Lowermost Stratosphere) to probe stratospheric air during the Arctic winter in 2015/2016 (Oelhaf et al., 2019). Flights of the PGS campaign were conducted from 17 December 2015 until 18 March 2016 and can be separated into two main phases. For this study, only the flights from the second main phase from 26 February to 18 March are investigated, since they took place in a comparable period (later winter). A separation into vortex, vortex boundary, and mid-latitudes measurements is based on the above mentioned method based on $\mathrm{N}_{2} \mathrm{O}$ measurements performed by the TRIHOP instrument on board of HALO during PGS (Krause et al., 2018) (see Figure S. 9 in the supporting information). As shown in section 4.2, the indirect method for the determination of $\mathrm{Cl}_{\mathrm{y}}$, where a direct measurement of all relevant chlorinated substances is not possible, proves to be comparable. During PGS, CFC-12 was measured with the ECD channel but the MS channel was in NCI 
mode and could not measure all chlorinated substances. $\mathrm{Cl}_{\mathrm{y}}$ was therefore calculated using the indirect method and $\mathrm{CFC}-12$ measurements from the GhOST-ECD channel during PGS. As for SouthTRAC, the scaled correlations from observations of the cryogenic whole-air sampling on two balloon flights inside the Arctic polar vortex in 2019 and 2011 were used (correlation function for the Arctic winter 2015/2016 can be taken from the supporting information).

Fig. 9 displays the mean vertical profiles of $\mathrm{Cl}_{\mathrm{y}}$ inside the vortex and $\mathrm{Cl}_{\text {tot }}$ of the respective hemisphere. The vertical coordinate of the classification was selected according to the displayed vertical coordinate. Measurements from the individual campaigns have been binned into $5 \mathrm{~K}$ potential temperature (a) and potential temperature difference to the local tropopause (b). The thermal tropopause according to WMO was used for PGS, as it was done for the SouthTRAC analysis. The PGS campaign averaged tropopause for the time period was at $315 \mathrm{~K}$ and slightly above the climatological tropopause of $309 \mathrm{~K}$ (NCEP Reanalysis Derived data provided by the NOAA/OAR/ESRL PSL, Boulder, Colorado, USA) whereas the campaign averaged tropopause during SouthTRAC was found to be at $320 \mathrm{~K}$ and therefore below the climatological tropopause of $327 \mathrm{~K}$. Independent of the vertical coordinate, abundance of total chlorine $\left(\mathrm{Cl}_{\text {tot }}\right)$ was lower in the stratosphere from the time of PGS (2015/2016) to the time of SouthTRAC (2019).

Using $\Theta$ as the vertical coordinate (Fig. 9a), vertical profiles of vortex classified $\mathrm{Cl}_{\mathrm{y}}$ of PGS and SouthTRAC show different results. Although the $\mathrm{Cl}_{\mathrm{y}}$ vortex profiles are similar until around $350 \mathrm{~K}$, the SouthTRAC profile increased stronger and values become more than $435 \mathrm{ppt}$ larger than during PGS within the vortex at equal potential temperatures. Differences become slightly larger when using $\Delta \Theta$ as the vertical coordinate (Fig 9b). Inside the vortex of the respective hemisphere, $\mathrm{Cl}_{\mathrm{y}}$ increased stronger with height above the tropopause during SouthTRAC than during PGS. Although close together between 20 and $25 \mathrm{~K}$ $\Delta \Theta$, the difference of $\mathrm{Cl}_{\mathrm{y}}$ increased to $565 \mathrm{ppt}$ at $65 \mathrm{~K} \Delta \Theta$.

Fig. 10 shows the difference between PGS and SouthTRAC Cl $\mathrm{y}_{\mathrm{y}}$ in a latitude-altitude cross section. As a horizontal coordinate, equivalent latitude* was used, i. e. the latitude for all tropospheric observations and equivalent latitude for all stratospheric ones (Keber et al., 2020). As a vertical coordinate, $\Delta \Theta$ was used. Since the tropopause height of each respective hemisphere is different and changes with the season, the tropopause relative coordinate $\Delta \Theta$ accounts for tropopause variability and better allow for comparison of $\mathrm{Cl}_{\mathrm{y}}$. The data have been binned in $5^{\circ}$ latitude and $5 \mathrm{~K}$ of potential temperature relative to the local tropopause. The difference was calculated by subtracting each Southern Hemispheric latitude-altitude bin from the equivalent Northern Hemispheric latitude-altitude bin. Values in the troposphere differ only slightly. In the lower stratosphere, a separation into two areas can be seen. In the lower stratosphere at higher latitudes overall higher mixing ratios were derived during SouthTRAC in comparison to PGS. Differences between SouthTRAC and PGS amount to $601 \mathrm{ppt}$ at maximum between 65 and $70 \mathrm{~K}$ of $\Delta \Theta$ and 65 to $70^{\circ}$ equivalent latitude. The stratosphere of the mid-latitudes shows consistently higher $\mathrm{Cl}_{\mathrm{y}}$ values during PGS. Highest levels of $\mathrm{Cl}_{\mathrm{y}}$ reach $386 \mathrm{ppt}$ more $\mathrm{Cl}_{\mathrm{y}}$ during PGS between 65 and $70 \mathrm{~K}$ of $\Delta \Theta$ and 40 to $45^{\circ}$ equivalent latitude. It must be noted that the polar vortex of each hemisphere is different in size, stability and strength of the transport barrier. The comparison on equivalent latitude is therefore only possible to a limited extent. The lowest $20 \mathrm{~K}$ above the local tropopause show sporadic impact of the stronger Antarctic vortex with an exception of one bin between 15 and $20 \mathrm{~K}$ of $\Delta \Theta$ and 65 to $70^{\circ}$ equivalent latitude with $412 \mathrm{ppt}$ more $\mathrm{Cl}_{\mathrm{y}}$ during SouthTRAC. However, it is in general affected by cross tropopause mixing for both hemispheres leading to almost zero differences in the extratropical tropopause layer (ExTL). 


\section{Summary and Conclusion}

This study is based on high-resolution measurements of chlorinated hydrocarbons and $\mathrm{N}_{2} \mathrm{O}$ taken during the SouthTRAC campaign in the Antarctic lower stratosphere in late austral winter 2019. Using an extended method according to Greenblatt et al. (2002a), it was possible to allocate the measurements to the vortex, vortex boundary region, and mid-latitudes. Compared to coarser resolved PV, air mass classification based on high resolution in situ measurements of $\mathrm{N}_{2} \mathrm{O}$ offers the possibility to detect and account for even small structures such as vortex filaments. However, the weakness of this air mass classification appears near the tropopause, where it was difficult to make a distinction between vortex, vortex boundary, and mid-latitudes. The thermal WMO tropopause was used in this study, as no dynamical PV tropopause data is yet available for the SouthTRAC campaign. The dynamical tropopause seems to fit better with trace studies and has been widely used in past studies (e.g. Keber et al. (2020)). Hence, for future investigation, it is worthwhile to choose the dynamical PV tropopause instead of the thermal WMO tropopause.

Inorganic chlorine was calculated semi-directly from the GhOST-MS measurements of the major organic source gases and mean age as well as indirectly using a correlation adapted from observations of balloon flights in the Arctic polar vortex in 2009 and 2011. In order to compare the indirect method to the semi-direct method, first the measurements of the GhOST-MS were up-sampled to a higher time resolution. The simultaneous accurate measurements of CFC-12 on the GhOST-MS and GhOSTECD channel were used. The indirect method shows good agreement with the semi-direct method despite a time interval of 10 years and the use of measurements of the Northern Hemisphere. Thus the indirect method serves as a good alternative calculation of inorganic chlorine, in case not all organic source gases are measured.

2019 was a special year for the Antarctic polar vortex with extraordinary meteorological conditions, which led to a minor sudden stratospheric warming. The Antarctic polar vortex was weakened and shifted towards the eastern South Pacific and South America during SouthTRAC. Despite a weakened vortex, up to 50\% of the total chlorine could be found in inorganic form inside the vortex at highest $\Delta \Theta$ levels of $75 \mathrm{~K}$ above the tropopause. Furthermore, inorganic chlorine for mid-latitudes and vortex boundary region could be derived during SouthTRAC with only about $15 \%$ of the total chlorine in inorganic form in the mid-latitudes.

Measurements from the PGS campaign, which took place in the Arctic polar winter 2015/2016 were used to compare Arctic and Antarctic $\mathrm{Cl}_{\mathrm{y}}$. At the time of publication, it is not known that such a comparison has already been made. For PGS, $\mathrm{Cl}_{\mathrm{y}}$ was calculated using the indirect method based on scaled correlation from the observations of balloon flights in the Arctic polar vortex in 2009 and 2011. Additionally, region classification was done using $\mathrm{N}_{2} \mathrm{O}$ measurements, as for the Southern Hemisphere data. In contrast to the Antarctic polar vortex in 2019, the Arctic polar vortex in 2015/2016 was one of the strongest compared to previous years (Matthias et al., 2016). At a comparable level of $\Delta \Theta$ inside the vortex, only around $40 \%$ of total chlorine can be found in inorganic form, whereas roughly $20 \%$ can be found at mid-latitudes. Inside the respective vortex, the amount of $\mathrm{Cl}_{\mathrm{y}}$ was higher during SouthTRAC than during PGS by up to $565 \mathrm{ppt}$ (at the same $\Delta \Theta$ level). Trends due to the Montreal Protocol would be negative to about $-20 \mathrm{ppt} \mathrm{yr}^{-1}$, which is not evident in this comparison. The difference of $\mathrm{Cl}_{\mathrm{y}}$ inside the respective vortex is significant and even larger than the inter annual variations reported by Strahan et al. (2014). For the comparison of 
the Arctic and Antarctic $\mathrm{Cl}_{\mathrm{y}}$ in this study, only one winter of the respective hemisphere was investigated. Furthermore, the respective campaign only shows a section of the respective winter seasons. These sections do not match completely. For a more meaningful conclusion about the $\mathrm{Cl}_{\mathrm{y}}$ loading in the respective polar vortex, further sampling at different seasons and over several years would be required.

Investigating the difference of $\mathrm{Cl}_{\mathrm{y}}$ in a latitude-altitude cross section from PGS and SouthTRAC, higher values at higher latitudes can be found for SouthTRAC whereas higher values for the mid-latitude lower stratosphere can be found for PGS. In the troposphere and near the tropopause, differences become smaller. The enhanced values in the northern mid-latitudes lower stratosphere may be due to a stronger residual circulation on the northern winter hemisphere than in the southern winter hemisphere due to stronger Brewer-Dobson circulation, but could also be influenced by more mixing of vortex air to midlatitudes. The higher values from SouthTRAC in higher latitudes may reveal the difference in spatial extent, isolation, and location of the southern hemisphere vortex. The Arctic vortex exhibits a larger variability as it is more effected by weather systems or wave activity. The Antarctic vortex on the other side is larger and stronger and is less effected by wave disturbances.

Data availability. The observational data of the HALO flights during the SouthTRAC campaign are available via the HALO database https://halo-db.pa.op.dlr.de (last access: XY).

Author contributions. MJ and AE performed the study and MJ wrote the paper. Measurements were performed by MJ, TK, TS, TW, and AE (GhOST), and HB, H-CL and PH (UMAQS). All authors contributed to the final paper.

Acknowledgements. This work was done at the University of Frankfurt. Funding from BMBF Programme ROMIC-II under Grant nr. 01LG1908B (SCI-HI) and from the German science foundation (DFG) under grant numbers EN367/13-1, EN367/14-1 and EN367/16-1 and EN367/17-1 for the PGS and SouthTRAC campaigns. The authors would like to thank the DLR staff for the operation of the HALO and the support during the campaign as well as the coordinators and colleagues for a productive cooperation during the campaign. We further thank Jens-Uwe Grooß from the Forschungszentrum Jülich for the calculation of the tropopause and equivalent latitude for the HALO campaigns. The authors would further like to thank the site operators at the Cape Grim, Mace Head, Trinidad Head, Ragged Point, and Cape Matatula stations. AGAGE is supported principally by NASA (USA) grants to MIT and SIO, and also by: BEIS (UK) and NOAA (USA) grants to Bristol University; CSIRO and BoM (Australia): FOEN grants to Empa (Switzerland); NILU (Norway); SNU (Korea); CMA (China); NIES (Japan); and Urbino University (Italy). 


\section{References}

Bönisch, H., Engel, A., Curtius, J., Birner, T., and Hoor, P.: Quantifying transport into the lowermost stratosphere using simultaneous in-situ measurements of $\mathrm{SF}_{6}$ and $\mathrm{CO}_{2}$, Atmospheric Chemistry and Physics, 9, 5905-5919, https://doi.org/10.5194/acp-9-5905-2009, 2009.

Crutzen, P. J. and Arnold, F.: Nitric acid cloud formation in the cold Antarctic stratosphere: a major cause for the springtime 'ozone hole', Nature, 324, 651-655, https://doi.org/https://doi.org/10.1038/324651a0, 1986.

Daniel, J. S., Solomon, S., and Albritton, D. L.: On the evaluation of halocarbon radiative forcing and global warming potential, Journal of Geophysical Research, 100(D1), 1271-1285, https://doi.org/10.1029/94JD02516, 1995.

DLR: The Basis HALO Measurement and Sensor System (BAHAMAS), https://www.halo.dlr.de/instrumentation/basis.html, 2020.

Engel, A., Strunk, M., Müller, M., Haase, H. P., Levin, I., and Schmidt, U.: Temporal development of total chlorine in the high-latitude stratosphere based on reference distributions of mean age derived from CO2 and SF6, Journal of Geophysical Research, 107, ACH 1-1 -ACH 1-8, https://doi.org/10.1029/2001JD000584, 2002.

Engel, A., Bönisch, H., Brunner, D., Fischer, H., Franke, H., Günther, G., Gurk, C., Hegglin, M., Hoor, P., Königstedt, R., Krebsbach, M., Maser, R., Parchatka, U., Peter, T., Schell, D., Schiller, C., Schmidt, U., Spelten, N., Szabo, T., Weers, U., Wernli, H., Wetter, T., and Wirth, V.: Highly resolved observations of trace gases in the lowermost stratosphere and upper troposphere from the Spurt project: an overview, Atmospheric Chemistry and Physics, 6, 283-301, https://doi.org/10.5194/acp-6-283-2006, 2006.

Engel, A., Bönisch, H., Ostermöller, J., Chipperfield, M. P., Dhomse, S., and Jöckel, P.: A refined method for calculating equivalent effective stratospheric chlorine, Atmospheric Chemistry and Physics, 18, 601-619, https://doi.org/10.5194/acp-18-601-2018, 2018a.

Engel, A., Rigby, M., Burkholder, J. B., Fernandez, R. P., Froidevaux, L., Hall, B. D., Hossaini, R., Saito, T., Vollmer, M. K., and Yao, B.: Update on Ozone-Depletion Substances (ODSs) and other Gases of Interest to the Montral Protocol, chap. 1, 58, World Meteorological Organization, Geneva, Switzerland, 2018b.

Farman, J. C., Gardiner, B. G., and Shanklin, J. D.: Large losses of total ozone in Antarctica reveal seasonal ClOx/NOx interaction, Nature, $315,1985$.

Greenblatt, J. B., Jost, H.-J., Loewenstein, M., Podolske, J. R., Bui, T. P., Hurst, D. F., Elkins, J. W., Herman, R. L., Webster, C. R., Schauffler, S. M., Atlas, E. L., Newman, P. A., Lait, L. R., Müller, M., Engel, A., and Schmidt, U.: Defining the polar vortex edge from an N2O:potential temperature correlation, Journal of Geophysical Research, 107, SOL 10-1 - 10-9, https://doi.org/10.1029/2001JD000575, 2002a.

Greenblatt, J. B., Jost, H.-J., Loewenstein, M., Podolske, J. R., Hurst, D. F., Elkins, J. W., Schauffler, S. M., Atlas, E. L., Herman, R. L., Webster, C. R., Bui, T. P., Moore, F. L., Ray, E. A., Oltmans, S., Vömel, H., Blavier, J.-F., Sen, B., Stachnik, R. A., Toon, G. C., Engel, A., Müller, M., Schmidt, U., Bremer, H., Pierce, R. B., Sinnhuber, B.-M., Chipperfield, M., and Lefevre, F.: Tracerbased determination of vortex descent in the 1999/2000 Arctic winter, Journal of Geophysical Research, 107, SOL 22-1 - SOL 22-21, https://doi.org/10.1029/2001JD000937, 2002b.

Hall, T. M. and Plumb, R. A.: Age as a diagnostic of stratospheric transport, Journal of Geophysical Research, 99, 1059-1070, 1994.

Hartmann, D. L., Chan, K. R., Gary, B. L., Schoeberl, M. R., Newman, P. A., Martin, R. L., Loewenstein, M., Podolske, J. R., and Strahan, S. E.: Potential Vorticity and Mixing in the South Polar Vortex During Spring, Journal of Geophysical Research, 94, 11,625-11,640, https://doi.org/10.1029/JD094iD09p11625, 1989.

Hauck, M., Fritsch, F., Garny, H., and Engel, A.: Deriving stratospheric age of air spectra using an idealized set of chemically active trace gases, Atmospheric Chemistry and Physics, 19, 5269-5291, https://doi.org/10.5194/acp-19-5269-2019, 2019. 
Hoor, P., Fischer, H., and Lelieveld, J.: Tropical and extratropical tropospheric air in the lowermost stratosphere over Europe: A CO-based budget, Geophysical Research Letters, 32, L07 802, https://doi.org/10.1029/2004GL022018, 2005.

Keber, T., Bönisch, H., Hatrick, C., Hauck, M., Lefrancois, F., Obersteiner, F., Ringsdorf, A., Schohl, N., Schuck, T., Hossaini, R., Graf, P., Jöckel, P., and Engel, A.: Bromine from short-lived source gases in the extratropical northern hemispheric upper troposphere and lower stratosphere (UTLS), Atmospheric Chemistry and Physics, pp. 4105-4132, https://doi.org/10.5194/acp-20-4105-2020, 2020.

Krause, J., Hoor, P., Engel, A., Plöger, F., Grooß, J.-U., Bönisch, H., Keber, T., Sinnhuber, B.-M., Woiwode, W., and Oelhaf, H.: Mixing and ageing in the polar lower stratosphere in winter 2015/2016, Atmospheric Chemistry and Physics, 18, 6057-6073, https://doi.org/10.5194/acp-2017-955, 2018.

Manney, G. L. and Lawrence, Z. D.: The major stratospheric final warming in 2016: dispersal of vortex air and termination of Arctic chemical ozone loss, Atmospheric Chemistry and Physics, 16, 15 371-15 396, https://doi.org/10.5194/acp-16-15371-2016, 2016.

Marsing, A., Jurkat-Witschas, T., Grooß, J.-U., Kaufmann, S., Heller, R., Engel, A., Hoor, P., Krause, J., and Voigt, C.: Chlorine partitioning in the lowermost Arctic vortex during the cold winter 2015/2016, Atmospheric Chemistry and Physics, pp. 10757-10772, https://doi.org/10.5194/acp-19-10757-2019, 2019.

Matthias, V., Dörnbrack, A., and Stober, G.: The extraordinarily strong and cold polar vortex in the early nothern winter 2015/2016, Geophysical Research Letters, 43, 287-294, https://doi.org/10.1002/2016GL071676, 2016.

Molina, M. J. and Rowland, F. S.: Stratospheric sink for chlorofluoromethanes: chlorine atomic-catalysed destruction of ozone, Nature, 249, 1974.

Molina, M. J., Tso, T., Molina, L. T., and Wang, F. C.-Y.: Antarctic Stratospheric Chemistry of Chlorine Nitrate, Hydrogen Chloride, and Ice: Release of Active Chlorine, Science, 238, 1253-1257, https://doi.org/10.1126/science.238.4831.1253, 1987.

Müller, S., Hoor, P., Berkes, F., Bozem, H., Klingebiel, M., Reutter, P., Smit, H. G. J., Wendisch, M., Spichtinger, P., and Borrmann, S.: In situ detection of stratosphere-troposphere exchange of cirrus particles in the midlatitudes, Geophysical Research Letters, 42, 949-955, https://doi.org/10.1002/2014GL062556, 2015.

Nash, E. R., Newman, P. A., Rosenfield, J. E., and Schoeberl, M. R.: An objective determination of the polar vortex using Ertel's potential vorticity, Journal of Geophysical Research, 101, 9471-9478, 1996.

Newman, P. A., Kawa, S. R., and Nash, E. R.: On the size of the Antarctic ozone hole, Geophysical Research Letters, 31, L21 104, https://doi.org/10.1029/2004GL020596, 2004.

Newman, P. A., Daniel, J. S., Waugh, D. W., and Nash, E. R.: A new formulation of equivalent effective stratospheric chlorine (EESC), Atmospheric Chemistry and Physics, 7, 4537-4552, https://doi.org/10.5194/acp-7-4537-2007, 2007.

Obersteiner, F., Bönisch, H., Keber, T., O’Doherty, S., and Engel, A.: A versatile, refrigerant- and cryogen-free cryofocusing- thermodesorption unit for preconcentration of traces gases in air, Atmospher Measurement Techniques, 9, 5265-5279, https://doi.org/10.5194/amt9-5265-2016, 2016.

Oelhaf, H., Sinnhuber, B.-M., Woiwode, W., Bönisch, H., Bozem, H., Engel, A., Fix, A., Friedl-Vallon, F., Grooß, J.-U., Hoor, P., Johansson, S., Jurkat-Witschas, T., Kaufmann, S., Krämer, M., Krause, J., Kretschmer, E., Lörks, D., Marsing, A., Orphal, J., Pfeilsticker, K., Pitts, M., Poole, L., Preusse, P., Rapp, M., Riese, M., Rolf, C., Ungermann, J., Voigt, C., Volk, C. M., Wirth, M., Zahn, A., and Ziereis, H.: POLSTRACC: Airborne Experiment for Studying the Polar Stratosphere in a Changing Climate with the High Altitude and Long Range Research Aircraft (HALO), Bulletin of the American Meteorological Society, 100, 2634 - 2664, https://doi.org/10.1175/BAMS-D-180181.1, https://journals.ametsoc.org/view/journals/bams/100/12/bams-d-18-0181.1.xml, 2019. 
Ostermöller, J., Bönisch, H., Jöckel, P., and Engel, A.: A new time-independent formulation of fractional release, Atmospheric Chemistry and Physics, 17, 3785-3797, https://doi.org/10.5194/acp-17-3785-2017, 2017.

Plumb, I. C., Vohralik, P. F., and Ryan, K. R.: Normalization of correlations for atmospheric species with chemical loss, Journal of Geophysical Research, 104, 11,723-11,732, 1999.

Prinn, R. G., Weiss, R. F., Arduini, J., Arnold, T., DeWitt, H. L., Fraser, P. J., Ganesan, A. L., Gasore, J., Harth, C. M., Hermansen, O., Kim, J., Krummel, P. B., Li, S., Loh, Z. M., Lunder, C. R., Maione, M., Manning, A. J., Miller, B. R., Mitrevski, B., Mühle, J., O’Doherty, S., Park, S., Reimann, S., Rigby, M., Saito, T., Salameh, P. K., Schmidt, R., Simmonds, P. G., Steele, L. P., Vollmer, M. K., Wang, R. H., Yao, B., Yokouchi, Y., Young, D., and Zhou, L.: History of chemically and radiatively important atmospheric gases from the Advanced Global Atmospheric Gases Experiment (AGAGE), Earth System Science Data, 10, 985-1018, https://doi.org/10.5194/essd-10-985-2018, https://essd.copernicus.org/articles/10/985/2018/, 2018.

Rapp, M., Kaifler, B., Dörnbrack, A., Gisinger, S., Mixa, T., Reichert, R., Kaifler, N., Knobloch, S., Eckert, R., Wildmann, N., Giez, A., Krasauskas, L., Preusse, P., Geldenhuys, M., Riese, M., Woiwode, W., Friedl-Vallon, F., Sinnhuber, B.-M., de la Torre, A., Alexander, P., Hormaechea, J. L., Janches, D., Garhammer, M., Chau, J. L., Conte, F. F., Hoor, P., and Engel, A.: SOUTHTRAC-GW: An airborne field campaign to explore gravity wave dynamics at the world's strongest hotspot, Bulletin of the American Meteorological Society, pp. $1-60$, https://doi.org/10.1175/BAMS-D-20-0034.1, 2020.

Safieddine, S., Bouillon, M., Paracho, A.-C., Jumelet, J., Tencé, F., Pazmino, A., Goutail, F., Wespes, C., Bekki, S., Boynard, A., HadjiLazaro, J., Coheur, P.-F., Hurtmans, D., and Clerbaux, C.: Antarctic Ozone Enhancement During the 2019 Sudden Stratospheric Warming Event, Geophysical Research Letters, 47, 1-10, https://doi.org/10.1029/2020GL087810, 2020.

Sala, S., Bönisch, H., Keber, T., Oram, D. E., Mills, G., and Engel, A.: Deriving an atmospheric budget of total organic bromine using airborne in situ measurements from the western Pacific area during SHIVA, Atmospheric Chemistry and Physics, 14, 6903-6923, https://doi.org/10.5194/acp-14-6903-2014, 2014.

Schauffler, S. M., Atlas, E. L., Donnelly, S. G., Andrews, A., Montzka, S. A., Elkins, J. W., Hurst, D. F., Romashkin, P. A., Dutton, G. S., and Stroud, V.: Chlorine budget and partitioning during the Stratospheric Aersol and Gas Experiment (SAFE) III Ozone Loss and Validation Experiment (SOLVE), Journal of Geophysical Research, 108, ACH 7-1 - ACH 7-18, https://doi.org/10.1029/2001JD002040, 2003.

Schoeberl, M. R. and Hartmann, D. L.: The Dynamics of the Stratospheric Polar Vortex and Its Relation to Springtime Ozone Depletion, Science, 251, 46-52, https://doi.org/10.1126/science.251.4989.46, 1991.

510 Strahan, S. E. and Douglass, A. R.: Decline in Antarctic Ozone Depletion and Lower Stratospheric Chlorine Determined From Aura Microwave Limb Sounder Observations, Geophysical Research Letters, 45, 382-390, https://doi.org/10.1002/2017GL074830, 2018.

Strahan, S. E., Douglass, A. R., Newman, P. A., and Steenrod, S. D.: Inorganic chlorine variability in the Antarctic vortex and implivations for ozone recovery, Journal of Geophysical Research, 119, 14,098-14,109, https://doi.org/10.1002/2014JD022295, 2014.

Wargan, K., Weir, B., Manney, G. L., Cohn, S. E., and Livesey, N. J.: The Anomalous 2019 Antarctic Ozone Hole in the GEOS Constituent

Data Assimilation System With MLS Observations, Journal of Geophysical Research, 125, https://doi.org/10.1029/2020JD033335, 2020. Werner, A. S.: Quantifying Transport Into the Lowermost Stratosphere, Ph.D. thesis, Ghoethe University Frankfurt, 2006.

Wetzel, G., Oelhaf, H., Birk, M., de Lange, A., Engel, A., Friedl-Vallon, F., Kirner, O., Kleinert, A., Maucher, G., Nordmeyer, H., Orphal, J., Ruhnke, R., Sinnhuber, B.-M., and Vogt, P.: Partitioning and budget of inorganic and organic chlorine species observed by MIPAS-B and TELIS in the Arctic in March 2011, Atmospheric Chemistry and Physics, 15, 8065-8076, 2015. 
https://doi.org/10.5194/acp-2021-356

Preprint. Discussion started: 28 May 2021

(c) Author(s) 2021. CC BY 4.0 License.

(a)

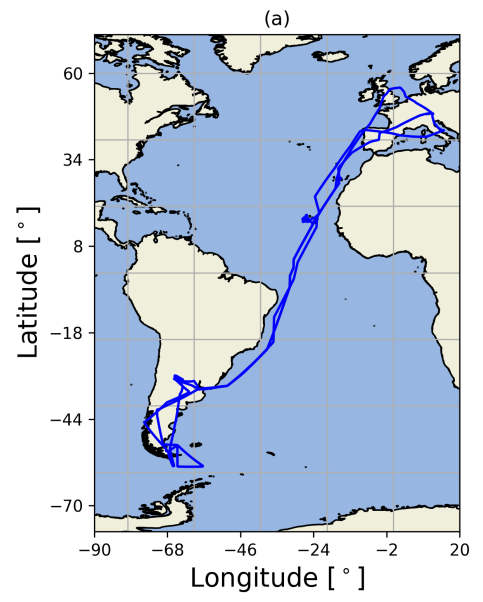

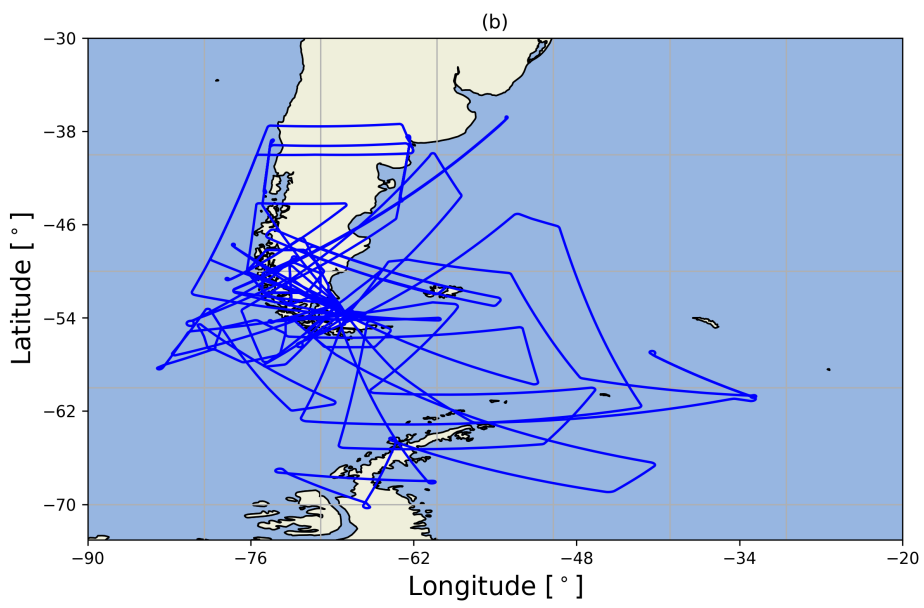

Figure 1. Flight tracks of HALO of (a) the transfers from and to Oberpfaffenhofen, Germany $\left(48^{\circ} \mathrm{N}, 11^{\circ} \mathrm{E}\right)$ and (b) during the two phases with the base in Rio Grande, Argentina $\left(53^{\circ} \mathrm{S}, 67^{\circ} \mathrm{W}\right)$. 
(a)

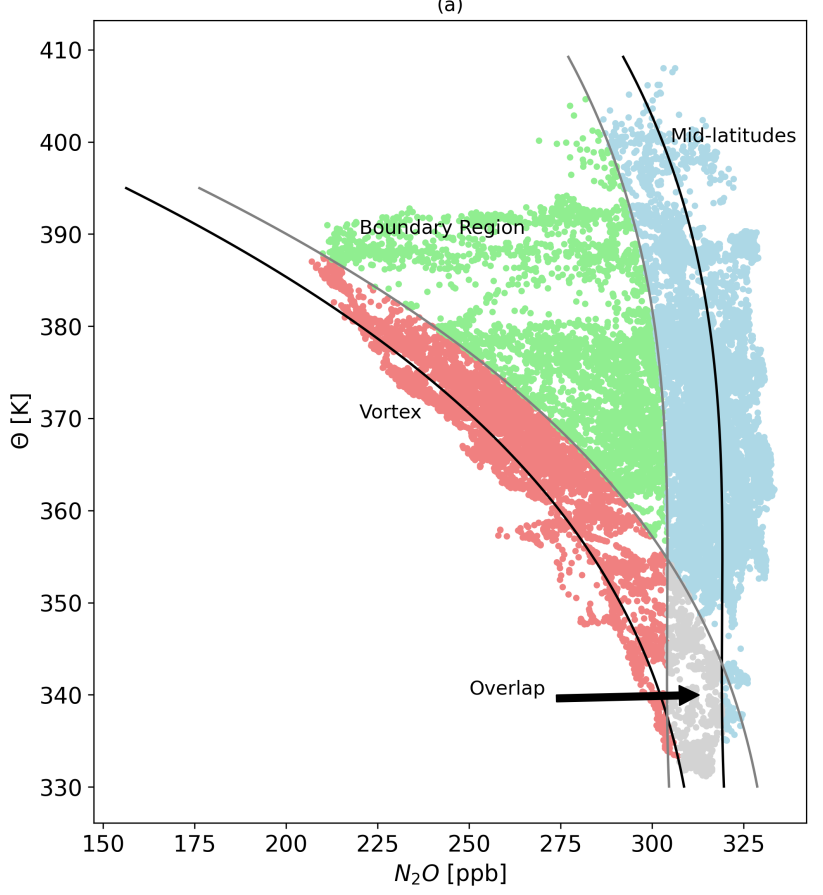

(b)

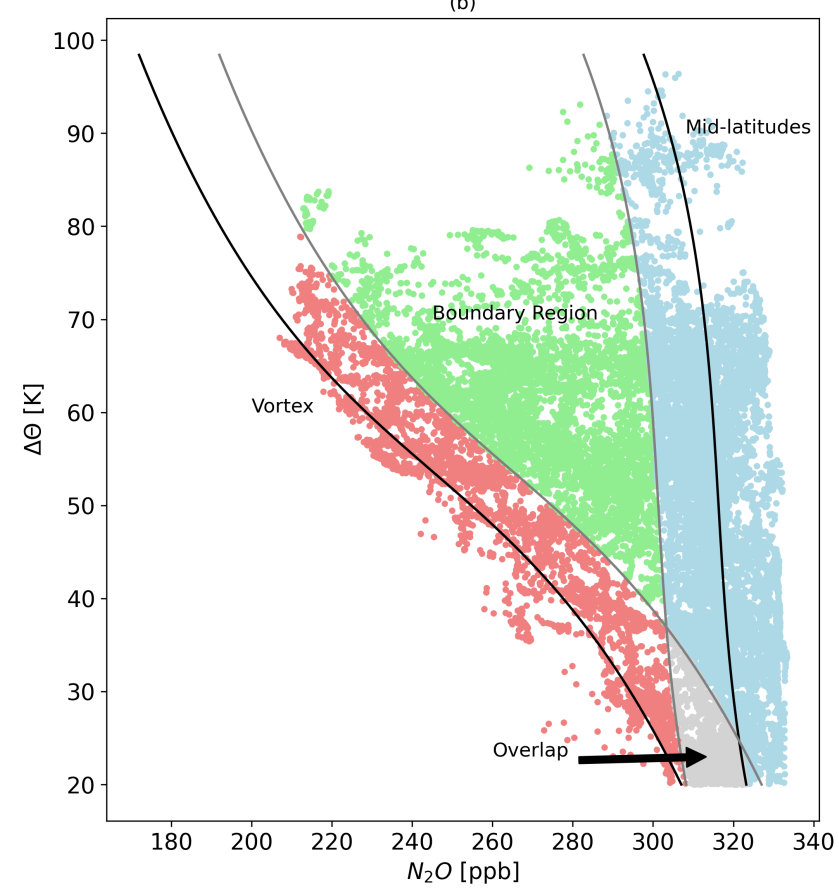

Figure 2. Mid-latitudes and vortex profiles (black) of $\mathrm{N}_{2} \mathrm{O}$ versus (a) potential temperature $(\Theta)$ and (b) potential temperature difference $(\Delta \Theta)$ to the local WMO tropopause. Cutoff criterion on $20 \mathrm{ppb}$ is illustrated by the the grey profile on the right side of the vortex profile. Mid-latitudes variability of $15 \mathrm{ppb}$ is illustrated with the grey profile on the left side of the mid-latitudes profile. In between, there is the vortex boundary region. Overlap region is declared for the area where cutoff and mid-latitudes variability crosses. Additionally, $\mathrm{N}_{2} \mathrm{O}$ measurements classified to the respective region are displayed. Vortex measurements in red, vortex boundary region measurements in green, mid-latitudes measurements in blue, and overlapping measurements in grey. 
https://doi.org/10.5194/acp-2021-356

Preprint. Discussion started: 28 May 2021

(c) Author(s) 2021. CC BY 4.0 License.
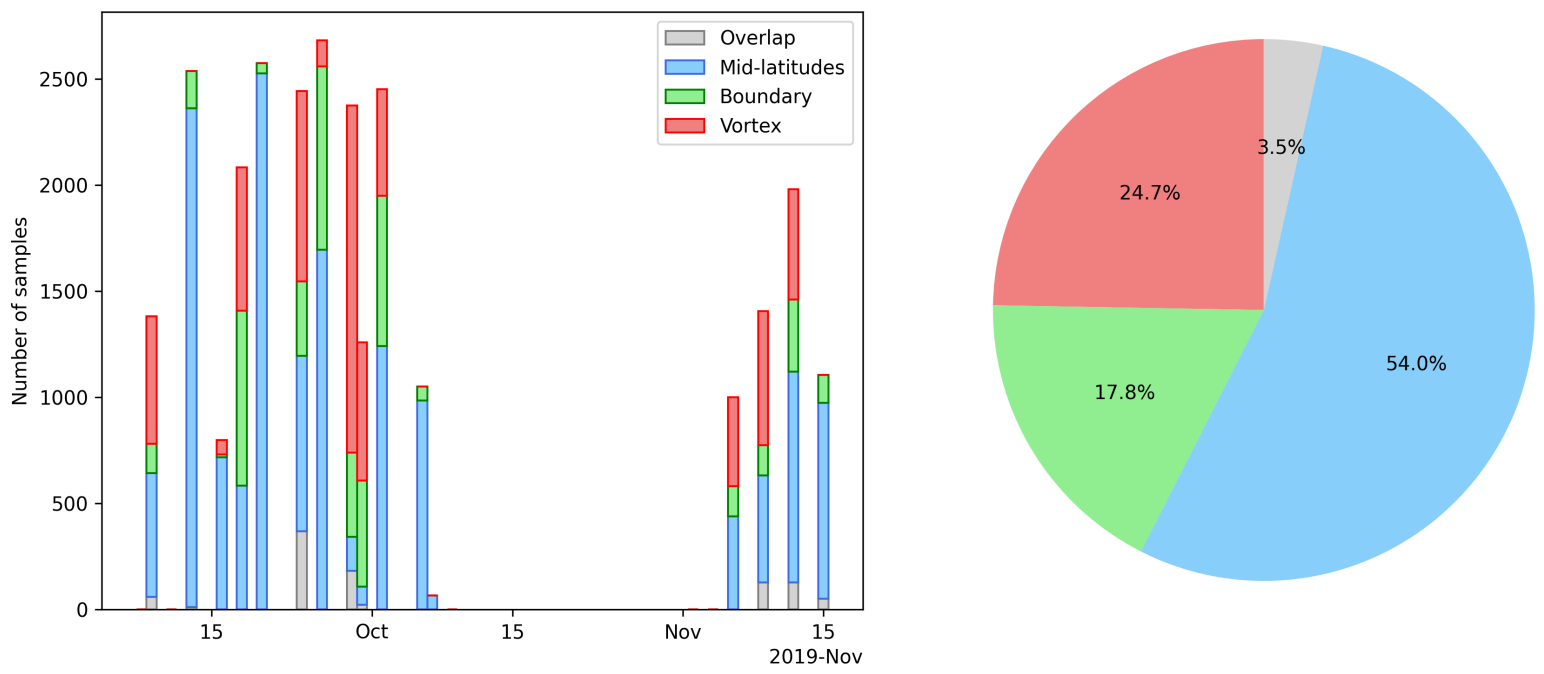

Figure 3. Air sampling statistics of the SouthTRAC campaign. On the left, the number of classified measurements. Each column represents a single scientific flight. Stacked bars indicate vortex (red), vortex boundary (green), mid-latitudes (blue), and undefined (grey) amounts. On the right side, percentage of each region to the total of all measurements in the scope of the classification (above $\Delta \Theta$ of $20 \mathrm{~K}$ ). 
https://doi.org/10.5194/acp-2021-356

Preprint. Discussion started: 28 May 2021

(c) Author(s) 2021. CC BY 4.0 License.

(c) (i)

\begin{tabular}{l} 
Atmospheric \\
Chemistry \\
and Physics \\
\hline Discussions
\end{tabular}

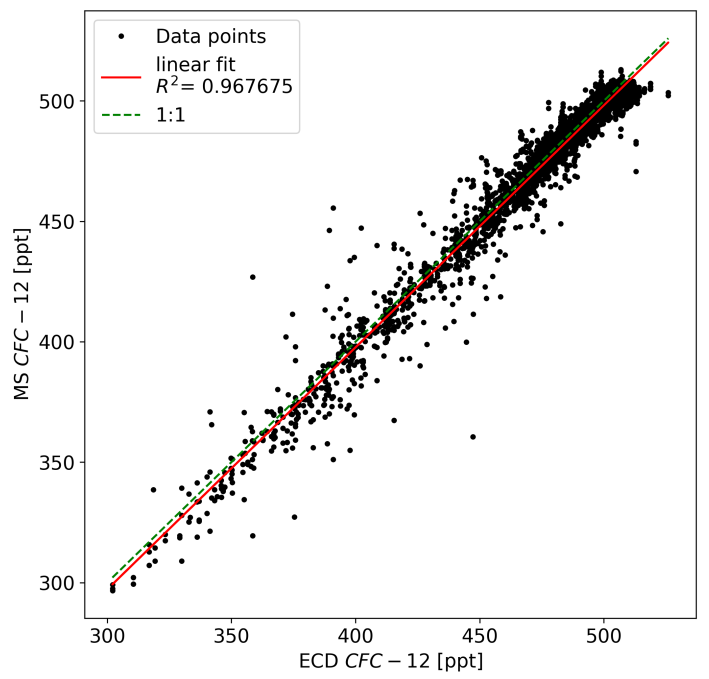

Figure 4. Correlation between CFC-12 measured on the GhOST-MS channel and on the GhOST-ECD channel. 
https://doi.org/10.5194/acp-2021-356

Preprint. Discussion started: 28 May 2021

(c) Author(s) 2021. CC BY 4.0 License.

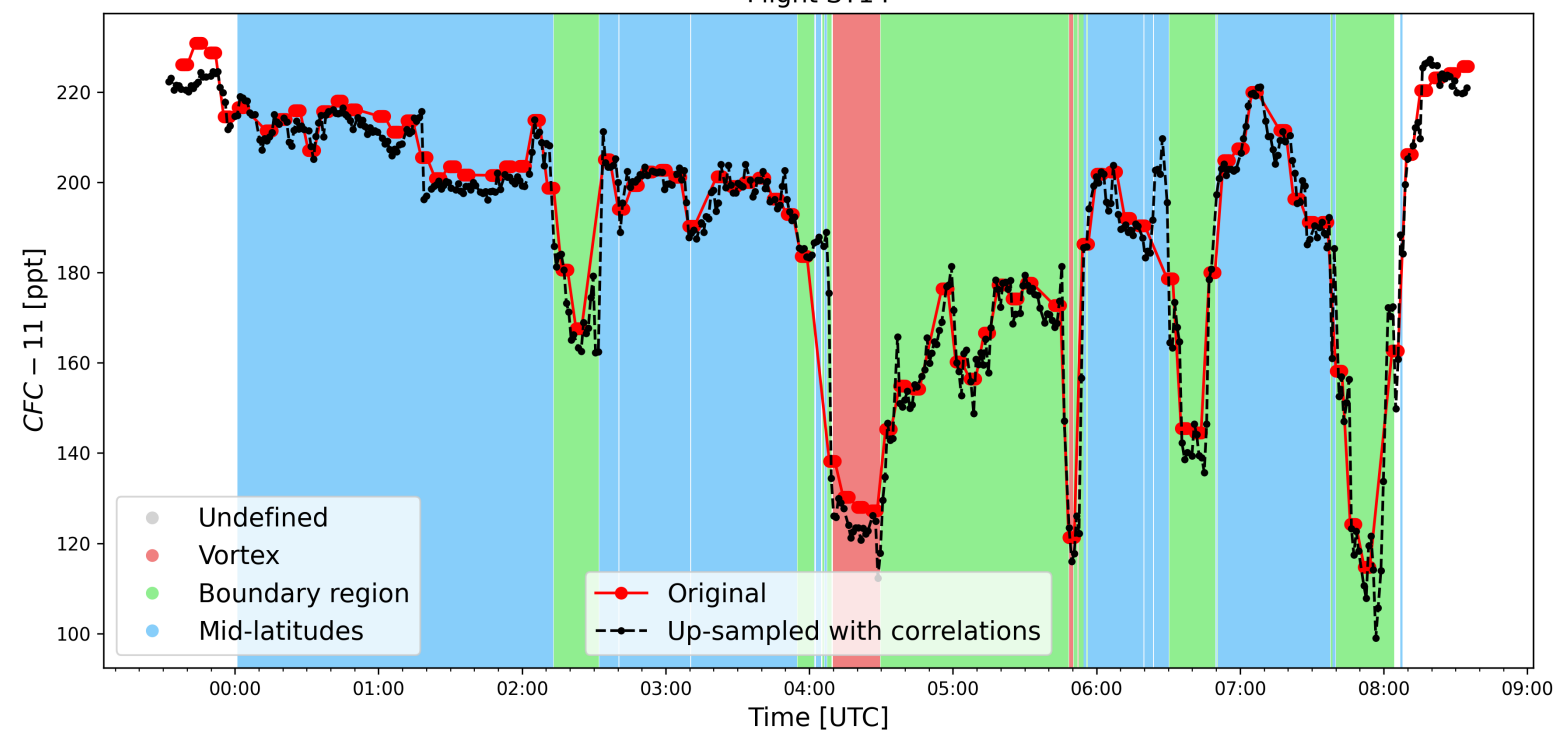

Figure 5. Comparison of CFC-11, measured on the GhOST-MS during flight ST14 on 26 September 2019. In red, original data, whereas is black, measurements were up-sampled using CFC-12 measurements of the ECD channel. Background colors indicate in which region the samples were taken, using the air mass classification in $\Theta$-coordinates. 
https://doi.org/10.5194/acp-2021-356

Preprint. Discussion started: 28 May 2021

(c) Author(s) 2021. CC BY 4.0 License.

(c) (i)
Atmospheric

Chemistry

and Physics

Discussions
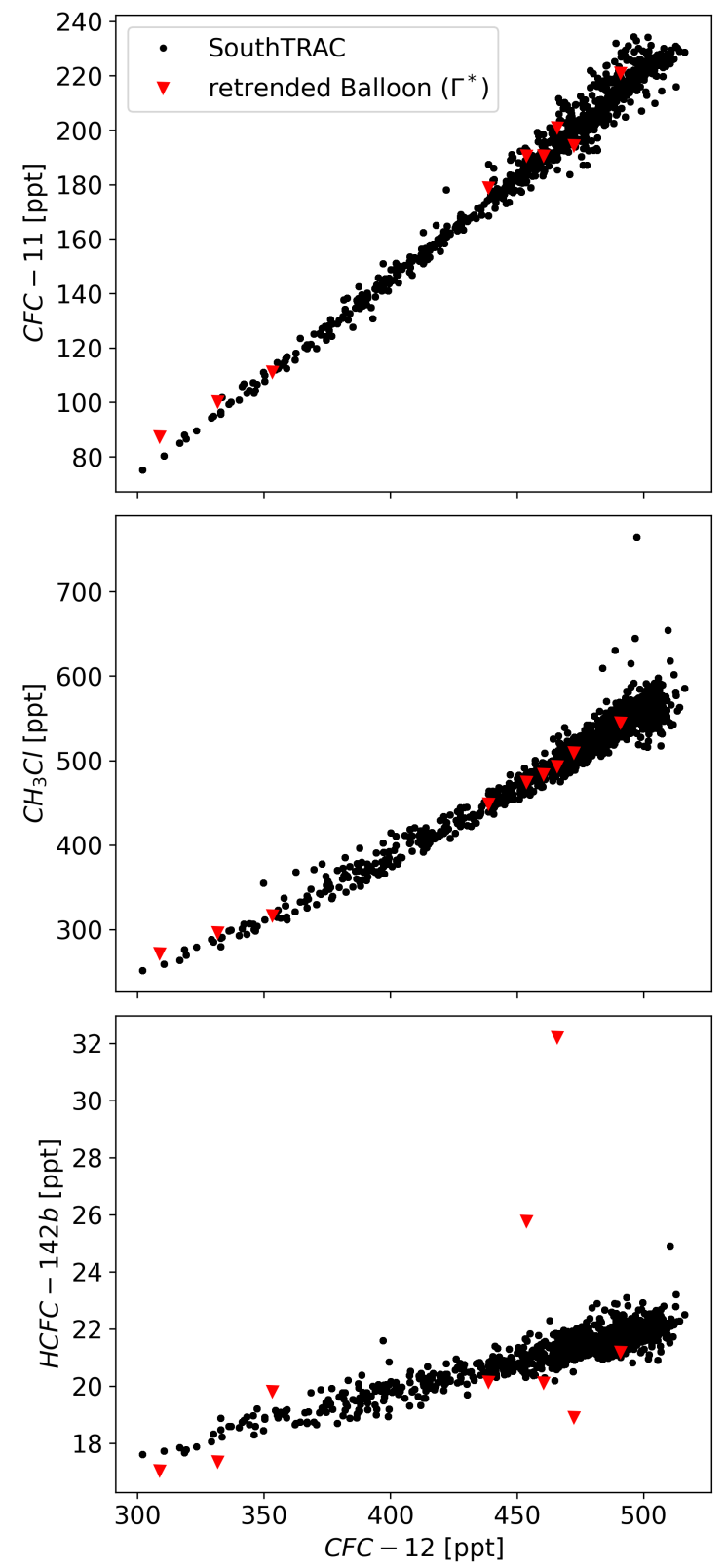

Figure 6. Correlation between $\mathrm{CFC}-12$ and $\mathrm{CFC}-11, \mathrm{CFC}-12$ and $\mathrm{CH}_{3} \mathrm{Cl}$, and between $\mathrm{CFC}-12$ and $\mathrm{HCFC}-142 \mathrm{~b}$. In black the measurements by GhOST-MS, in red the retrended balloon observations using mean $22^{\text {rrival time. }}$ 
https://doi.org/10.5194/acp-2021-356

Preprint. Discussion started: 28 May 2021

(c) Author(s) 2021. CC BY 4.0 License.

(c) (i)
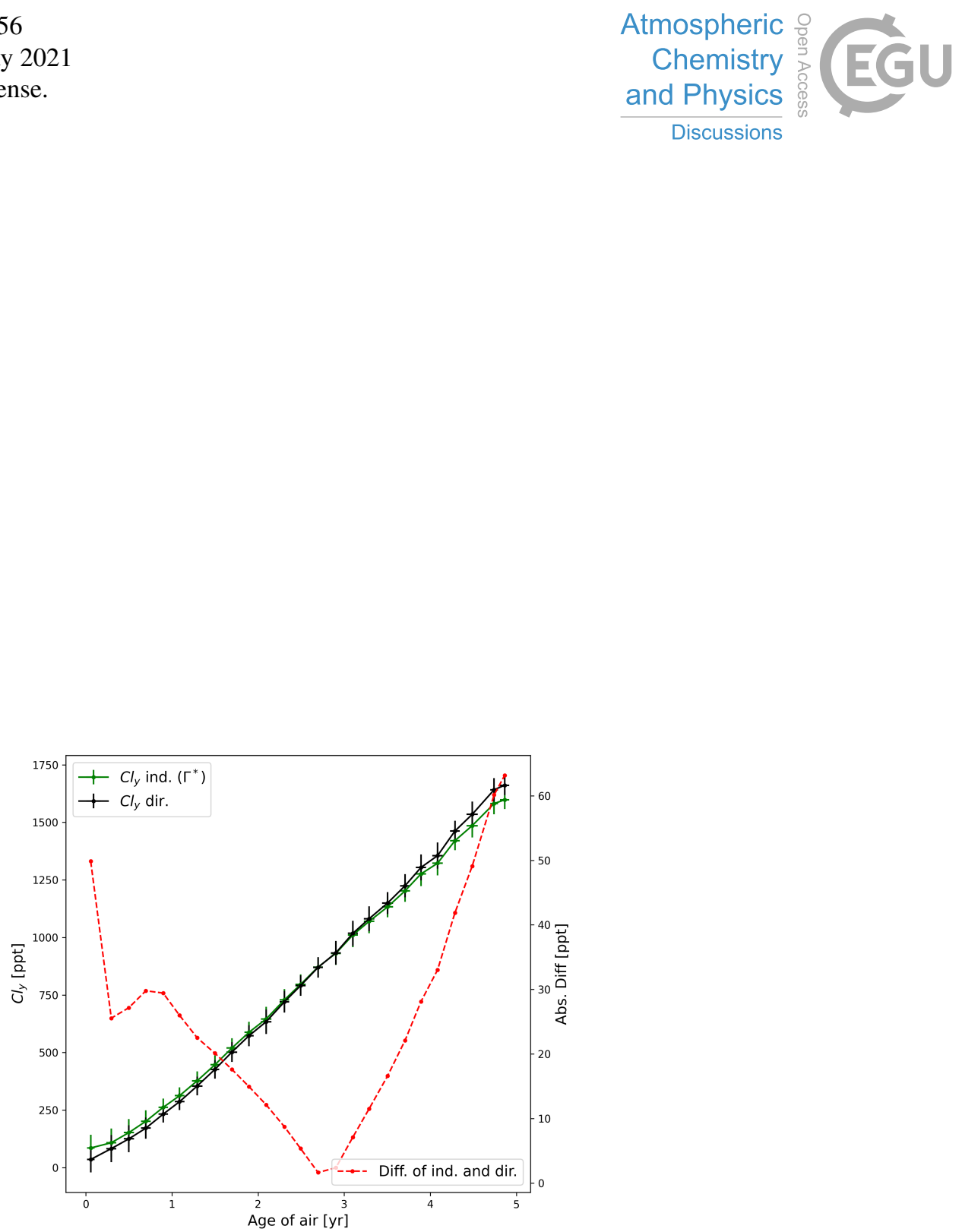

Figure 7. Indirectly and directly determined inorganic chlorine as a function of age of air (green and back) and the absolute difference between these methods (red). 
https://doi.org/10.5194/acp-2021-356

Preprint. Discussion started: 28 May 2021

(c) Author(s) 2021. CC BY 4.0 License.

(c) (i)

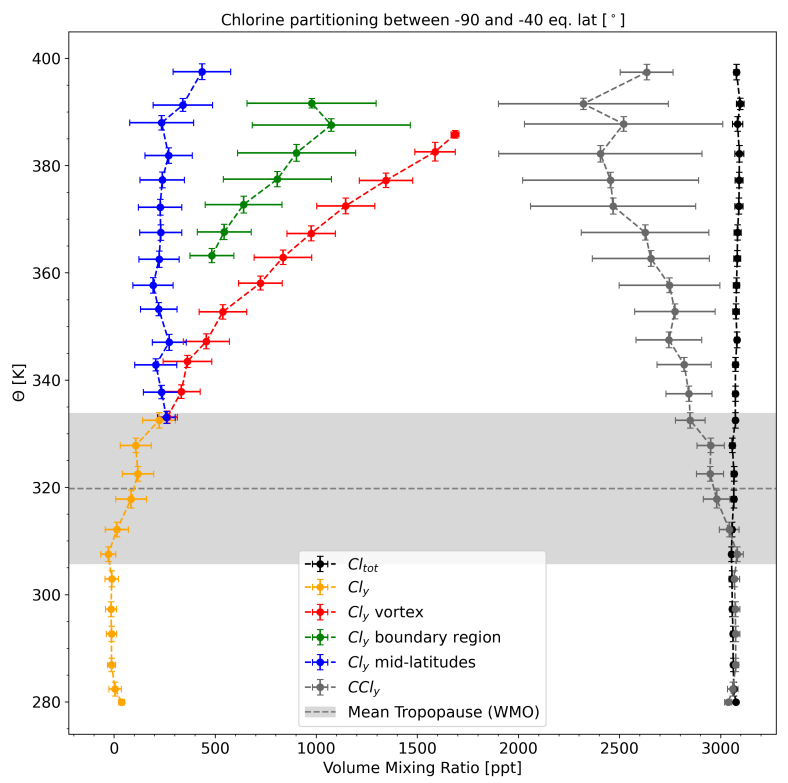

Figure 8. Vertical profiles of $\mathrm{Cl}_{y}, \mathrm{Cl}_{y}$ by region from $20 \mathrm{~K}$ above the local tropopause, $\mathrm{CCl}_{y}$, and $\mathrm{Cl}_{\text {tot }}$ averaged over $-90^{\circ}$ to $-40^{\circ}$ equivalent latitude for all flights during SouthTRAC. The data are displayed as a function of potential temperature. Vertical and horizontal error bars denote $1 \sigma$ variability. The dashed line shows the mean averaged WMO tropopause with the $1 \sigma$ variability as shaded area. 
https://doi.org/10.5194/acp-2021-356

Preprint. Discussion started: 28 May 2021

(c) Author(s) 2021. CC BY 4.0 License.

(a)

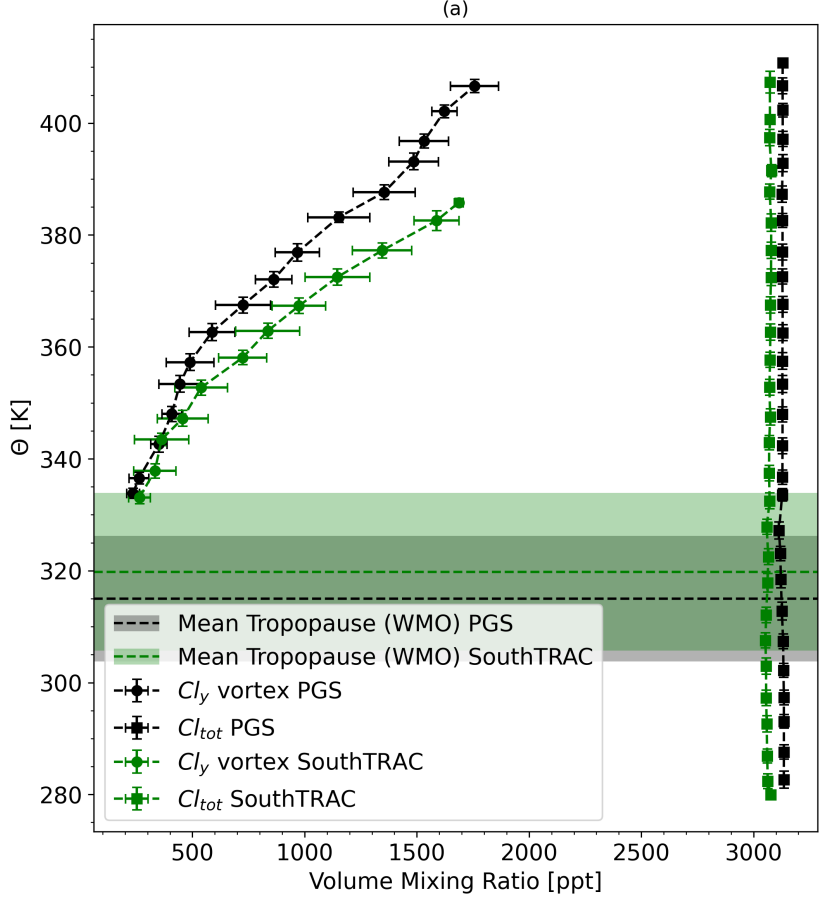

(b)

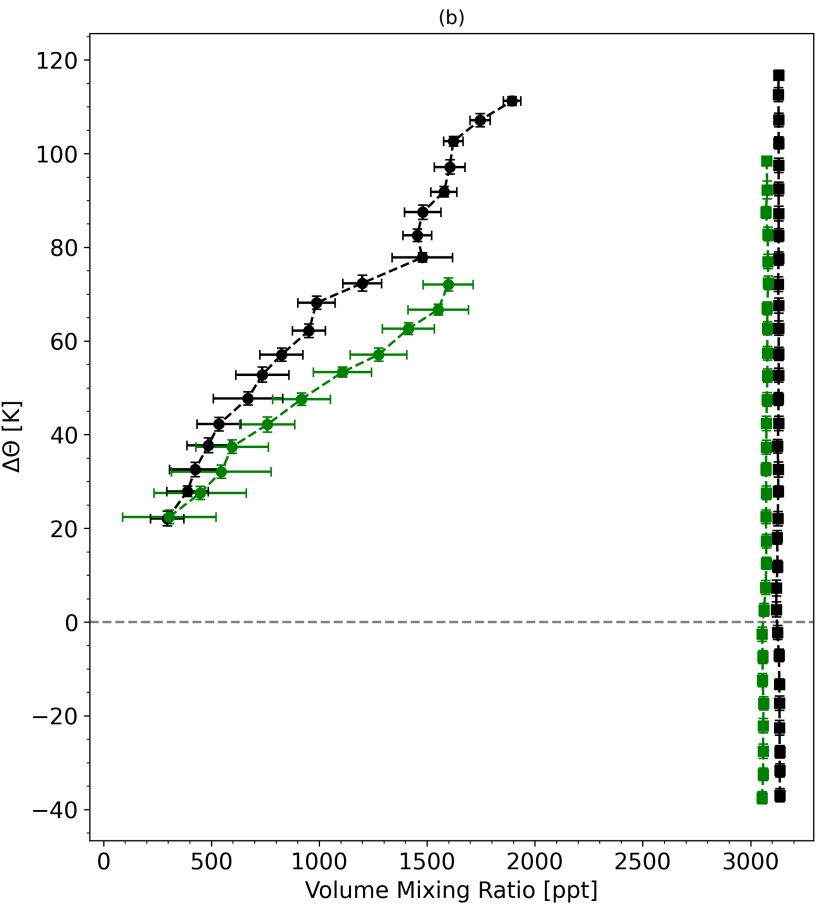

Figure 9. (a) Comparison of the vertical profiles of $\mathrm{Cl}_{y}$ inside the respective vortex where classification was possible as well as total chlorine from PGS (black) and SouthTRAC (green). Data are averaged over $40^{\circ}$ to $90^{\circ}$ of the respective hemisphere and are displayed as a function of potential temperature and as a function of potential temperature difference to the local tropopause. Vertical and horizontal error bars denote $1 \sigma$ variability. As dashed horizontal lines with the $1 \sigma$ variability as shaded areas, mean averaged WMO tropopauses for PGS (black) and SouhTRAC (green) are displayed. (b) as in (a) but as a function of potential temperature relative to the local tropopause (WMO), displayed with a grey dashed line. 
https://doi.org/10.5194/acp-2021-356

Preprint. Discussion started: 28 May 2021

(c) Author(s) 2021. CC BY 4.0 License.

(c) (i)
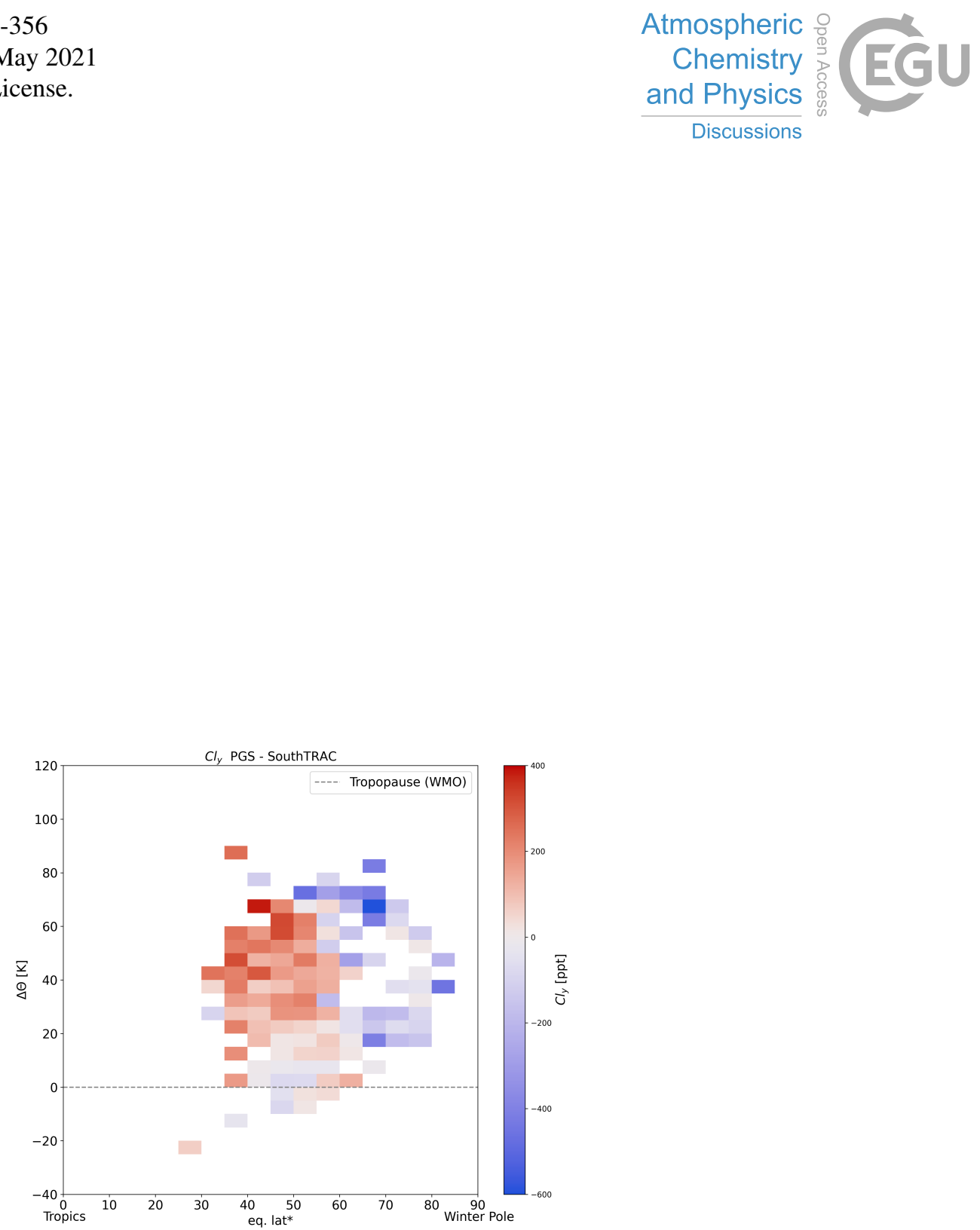

Figure 10. Difference of the latitude-altitude cross section of $\mathrm{Cl}_{y}$ from PGS and SouthTRAC. Data are binned using equivalent latitude ${ }^{*}$ and $\Delta \Theta$. 
https://doi.org/10.5194/acp-2021-356

Preprint. Discussion started: 28 May 2021

(c) Author(s) 2021. CC BY 4.0 License.

(c) (i)

Table 1. Chlorinated species measured with the GhOST- MS. Precisions and limit of detection (LOD) of GhOST have been determined shortly before the SouthTRAC (ST) campaign and mean precisions during the flights.

\begin{tabular}{llll|l}
\hline & & \multicolumn{2}{c|}{ Laboratory } & ST \\
\cline { 3 - 5 } Name & Formula & Prec. & LOD & Prec. \\
& & $(\%)$ & $(\mathrm{ppt})$ & $(\%)$ \\
\hline CFC-11 & $\mathrm{CCl}_{3} \mathrm{~F}$ & 0.22 & 0.36 & 1.13 \\
CFC-12 & $\mathrm{CCl}_{2} \mathrm{~F}_{2}$ & 0.30 & 0.47 & 0.71 \\
CFC-113 & $\mathrm{C}_{2} \mathrm{Cl}_{3} \mathrm{~F}_{3}$ & 0.64 & 0.18 & 2.93 \\
Methyl chloride & $\mathrm{CH}_{3} \mathrm{Cl}_{2}$ & 0.39 & 0.76 & 1.11 \\
Tetrachloromethane & $\mathrm{CCl}_{4}$ & 0.44 & 0.22 & 0.98 \\
Methyl chloroform & $\mathrm{CH}_{3} \mathrm{CCl}_{3}$ & 8.67 & 0.53 & 3.76 \\
HCFC-22 & $\mathrm{CHClF}_{2}$ & 0.41 & 1.31 & 0.84 \\
HCFC-141b & $\mathrm{C}_{2} \mathrm{H}_{3} \mathrm{Cl}_{2} \mathrm{~F}$ & 0.82 & 0.39 & 1.23 \\
HCFC-142b & $\mathrm{C}_{2} \mathrm{H}_{3} \mathrm{ClF}_{2}$ & 0.84 & 0.50 & 1.63 \\
\hline
\end{tabular}

Table 2. Coefficients of the correlation function to derive $\mathrm{Cl}_{\mathrm{y}}$ with the respective reference substance for the time of the SouthTRAC campaign (2019.75). Calculation of $\mathrm{Cl}_{\mathrm{y}}$ with CFC-12 or $\mathrm{N}_{2} \mathrm{O}$ and coefficients based on the balloon observations in 2009 and 2011 (Balloon) as well as coefficients based on the SouthTRAC measurements (SouthTRAC).

\begin{tabular}{ll|lll}
\hline Data source & $\chi_{\text {ref }}$ & $\mathrm{c}_{0}[\mathrm{ppt}]$ & $\mathrm{c}_{1}$ & $\mathrm{c}_{2}\left[\mathrm{ppt}^{-1}\right]$ \\
\hline Balloon & CFC-12 & 2965.27 & -2.80700 & $-6.06944 * 10^{-3}$ \\
Balloon & $\mathrm{N}_{2} \mathrm{O}$ & 2990.74 & -2.16187 & $-2.10586^{*} 10^{-2}$ \\
SouthTRAC & CFC-12 & 3024.26 & -2.61888 & $-6.87717^{-3} 10^{-3}$ \\
(limited to about 300 ppt) & & & \\
SouthTRAC & $\mathrm{N}_{2} \mathrm{O}$ & 3884.40 & -8.02682 & $-1.14510^{*} 10^{-2}$ \\
(limited to about 250 ppb) & & & \\
\hline
\end{tabular}

